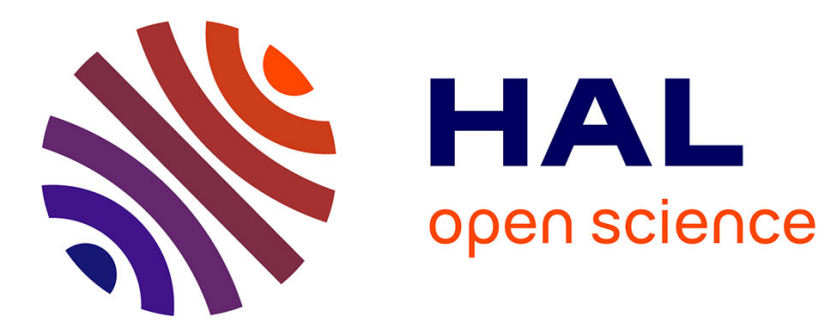

\title{
Physical Origin of Hot Spots in Pressed Explosive Compositions
}

\author{
R. Belmas, J.-P. Plotard
}

\section{To cite this version:}

R. Belmas, J.-P. Plotard. Physical Origin of Hot Spots in Pressed Explosive Compositions. Journal de Physique IV Proceedings, 1995, 05 (C4), pp.C4-61-C4-87. 10.1051/jp4:1995406 . jpa-00253705

\section{HAL Id: jpa-00253705 https://hal.science/jpa-00253705}

Submitted on 1 Jan 1995

HAL is a multi-disciplinary open access archive for the deposit and dissemination of scientific research documents, whether they are published or not. The documents may come from teaching and research institutions in France or abroad, or from public or private research centers.
L'archive ouverte pluridisciplinaire HAL, est destinée au dépôt et à la diffusion de documents scientifiques de niveau recherche, publiés ou non, émanant des établissements d'enseignement et de recherche français ou étrangers, des laboratoires publics ou privés. 


\title{
Physical Origin of Hot Spots in Pressed Explosive Compositions
}

\author{
R. Belmas and J.-P. Plotard* \\ Commissariat à l'Energie Atomique, Centre d'Etudes du Ripault, BP. 16, 37260 Monts, France \\ * Commissariat à l'Energie Atomique, Centre d'Etudes de Vaujours-Moronvilliers, BP. 7, 77181 Courtry, \\ France
}

\begin{abstract}
We present a complete experimental and theoretical study of hot spots generation in pressed explosive compositions. First, the results of experiments leading to the identification of the hot spots origin are detailed. Then, using these results, a physical model is developed. Three applications are presented. The firts one is devoted to the study of the sensitivity of mixed HMX/TATB compositions. The second one deals with double shock desensitization. The third one is the development of an efficient SDT kinetics using the hot spot model previously described.
\end{abstract}

\section{1 - INTRODUCTION}

Hot spot generation is now well-recognized as the initial mechanism governing shock-to-detonation transition.

The study of hot spot formation is difficult due to high temperature $(\sim 1000 \mathrm{~K})$ and pressure (from $0.1 \mathrm{GPa}$ to several $10 \mathrm{GPa}$ ) involved in this phenomenon, short duration (from a few ns to a few $\mu \mathrm{s}$ ), very small size of the areas of interest ( $\leq$ a few microns), opacity of the considered media and decomposition phenomena generating heat, gases and pressure.

To overcome these difficulties, original experiments were carried out in order to identify the origin of the hot spots. The knowledge of this phenomenology then allowed us to develop a physical model of hot spots formation and ignition.

This model itself is a powerful tool which can be used to analyze complex initiation mechanisms like the ones occurring in mixed explosive compositions or in the case of double shocks.

Another application of interest is the association of such a model with a grain burning law in order to develop an efficient and physical kinetics able to simulate all the phenomena involved in the shock-todetonation transition.

\section{2 - HOT SPOTS : PHENOMENOLOGY - EXPERIMENTS [1]}

\subsection{Possible origin of hot spots}

The hot spots are generated by the interaction between shock waves and heterogeneities of the microstructure of the explosive. 
Several heterogeneities can be at the origin of hot spots :

- porosity,

- binder [2] [3].

In the same way, different mechanisms can be invoked, for hot spot formation, during pore collapse :

- hydrodynamic mechanism [4],

- heating of trapped gases [5][6],

- viscoplastic work in the explosive around the pores [7][8][9].

As mentioned in the introduction, direct observation is very difficult and we performed comparative experiments to evaluate the respective importance of each mechanism.

\subsection{Relative influence of porosity and binder}

Experiments were performed on pressed TATB compositions and pure TATB samples pressed at different densities. In all cases, the same well-characterized TATB powder was used.

Gap-Test : the experimental set-up is presented in Figure 1.

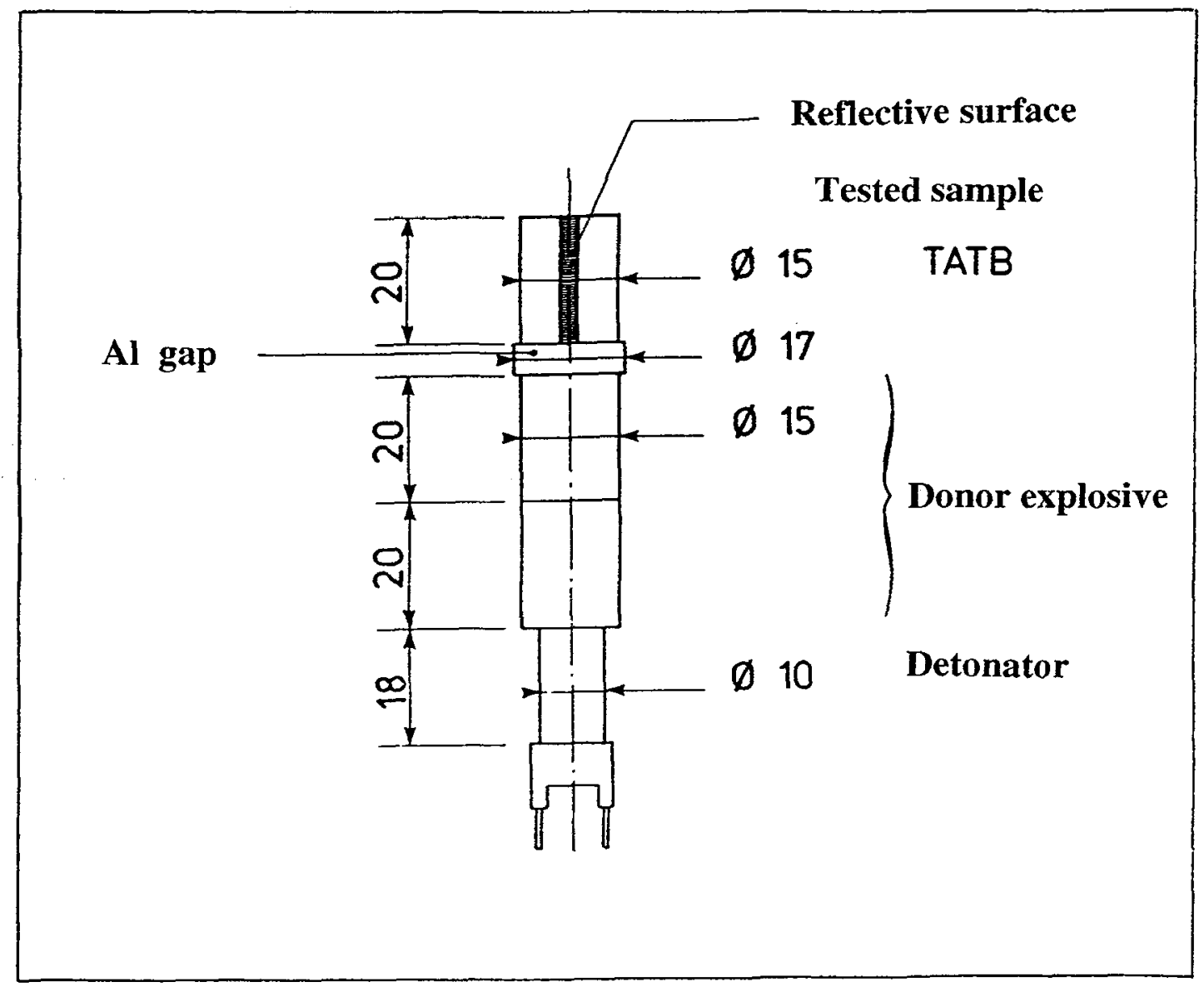


In addition to the go-no go results usually obtained with these experiments, we measured the run distance to detonation by observing the side of the sample with a streak camera to determine the $(x, t)$ diagrams. The experimental data are summarized in Figures 2 and 3 for TATB samples with densities between 1.0 and 1.875 , and TATB composition T2, which includes TATB powder, a few percent of binder and $2.3 \%$ of porosity. The removal of the binder from T2 leads to a 1.8 in density pure TATB sample.

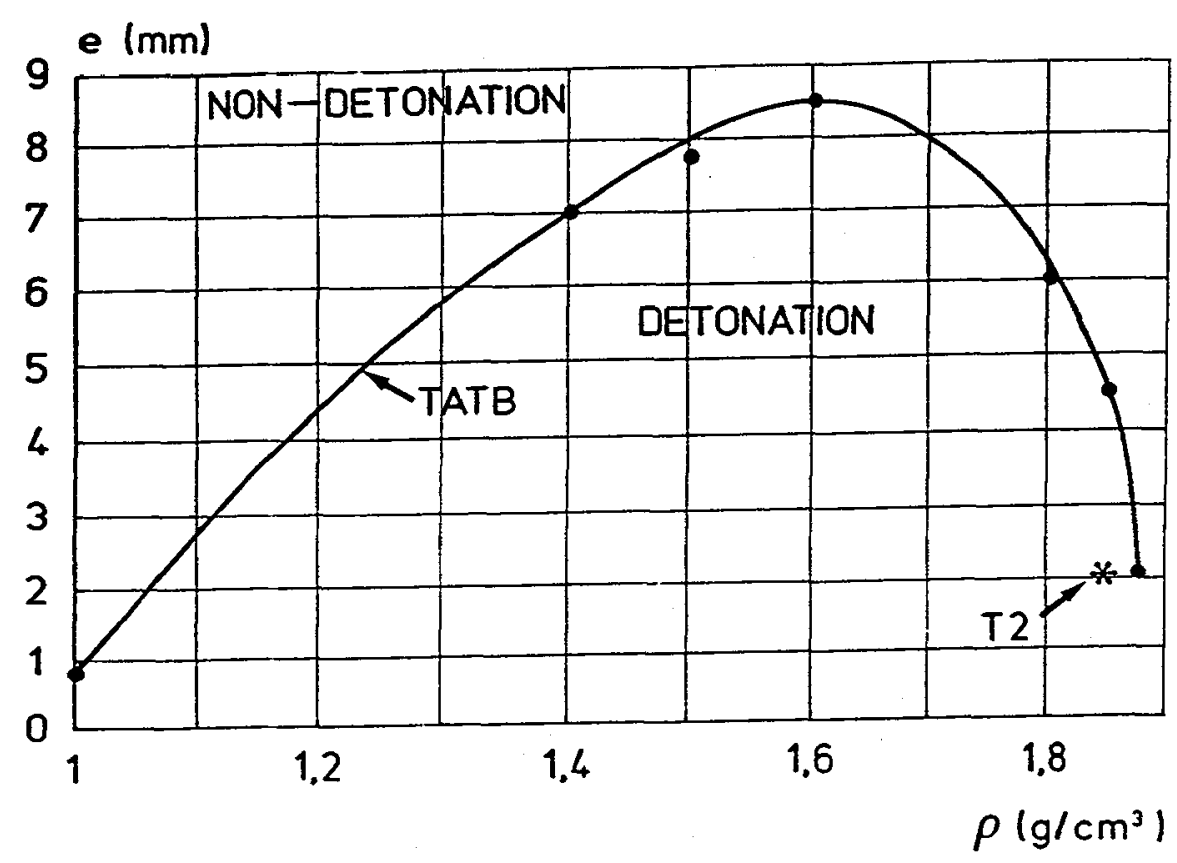

Figure 2 - GAP-TEST DATA

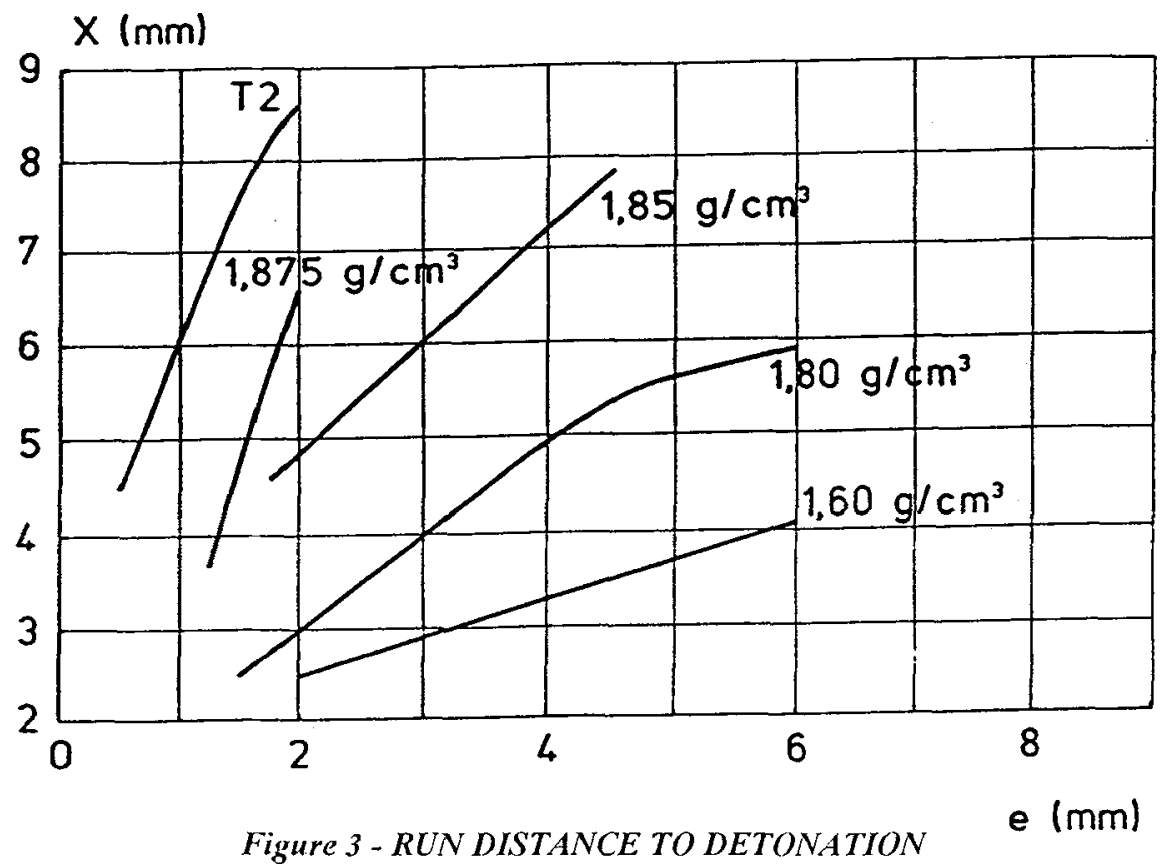


The analysis of Figures 2 and 3 shows that it is easier to initiate the powder without binder than the T2 composition. For the studied case, the binder has a negligible influence on the production of hot spots regarding to the influence of porosity.

Run distance to detonation : We performed wedge test experiments on three different TATB compositions based on the same explosive powder (Table 1). The three binders have very different chemical and mechanical properties. We obtained the same results (Figure 4) for T1 and T2, which have the same porosity. The T3 composition, which has a lower porosity, is more difficult to initiate. The results confirm our previous conclusion on the weak influence of the binder on hot spots formation process, regarding to the importance of porosity.

\begin{tabular}{|c|c|c|c|}
\hline (Corpostivir & TAB Powder & Buder & Porosity. \\
\hline $\mathrm{T} 1$ & $50 \mu \mathrm{m}$ & $\mathrm{B} 1$ & $2,6 \%$ \\
\hline $\mathrm{T} 2$ & 50 & $\mathrm{~B} 2$ & $2,3 \%$ \\
\hline $\mathrm{T} 3$ & 50 & $\mathrm{~B} 3$ & $1,4 \%$ \\
\hline
\end{tabular}

Table I - TATB COMPOSITIONS

Short duration shock initiation: The threshold curves (Figure 5) obtained for T1, T2 and T3 lead to the same conclusion as before about the relative influence of binder and porosity.

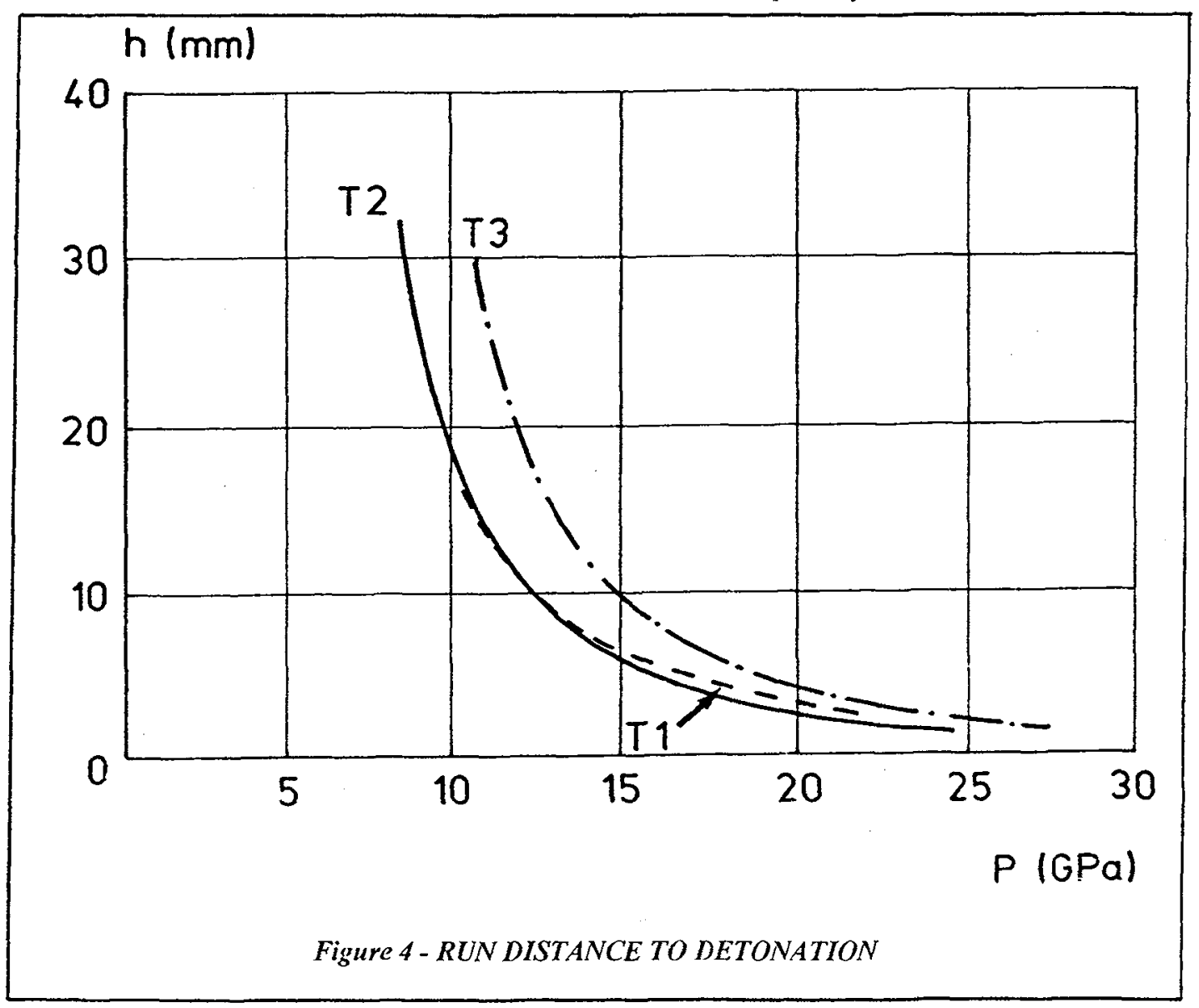




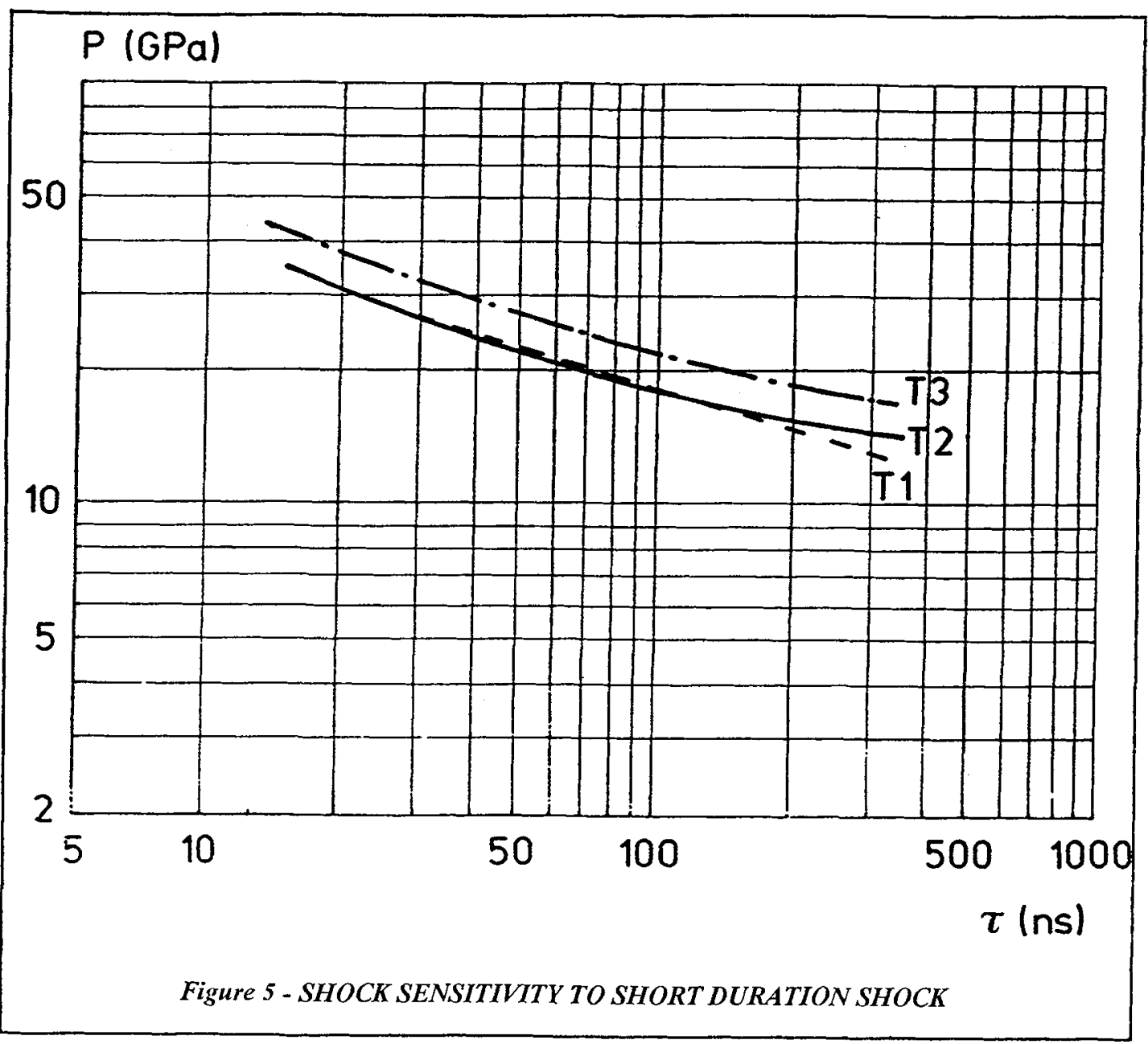

\subsection{Effective mechanism governing hot spots formation}

We showed that in our pressed explosive compositions, the hot spots are created by the collapse of the pores. Some of the previously presented Gap-Test experiments, which were realised in the room atmosphere, were performed under vacuum. The same results, including the $(x, t)$ diagrams, were obtained. Therefore, the compression of the gas contained in the voids has no influence on the initiation of the explosive.

It is not so easy to have experimental data and make a choice between a hydrodynamic and a viscoplastic collapse of the voids. R.B. FREY [9] developed a dimensional analysis of this problem. His conclusion can be summarised as follow :

if $\mathrm{Nl}=\frac{\mathrm{a}_{0} \frac{\mathrm{dP}}{\mathrm{dt}} \sqrt{\frac{\rho}{\mathrm{y}}}}{\mathrm{Y}}$

and $\mathrm{N} 2=\frac{\mathrm{a} 0 \sqrt{\rho \mathrm{P}}}{\mu}$ 
with $\quad a_{0}$ : initial pore radius (assumed spherical)

$\mathrm{P}$ : pressure

$\mathrm{t}$ : time

$Y:$ yield strength

$\rho:$ explosive crystal density

$\mu$ : viscosity

then, to have a hydrodynamic mechanism, the two quantities $\mathrm{N} 1$ and $\mathrm{N} 2$ must be greater than one.

In a shock wave, $\mathrm{N} 1$ is always greater than one, but, as shown in Figure 6, the criterion is not fulfilled by $\mathrm{N} 2$ in our explosive compositions, in which the pores characteristic size lies between $0.1 \mu \mathrm{m}$ and $1 \mu \mathrm{m}$ and the viscosity (not well known), can lie between $100 \mathrm{~Pa}$.s and $1000 \mathrm{~Pa}$.s, as proposed by several authors [7] [10] [11] [12].

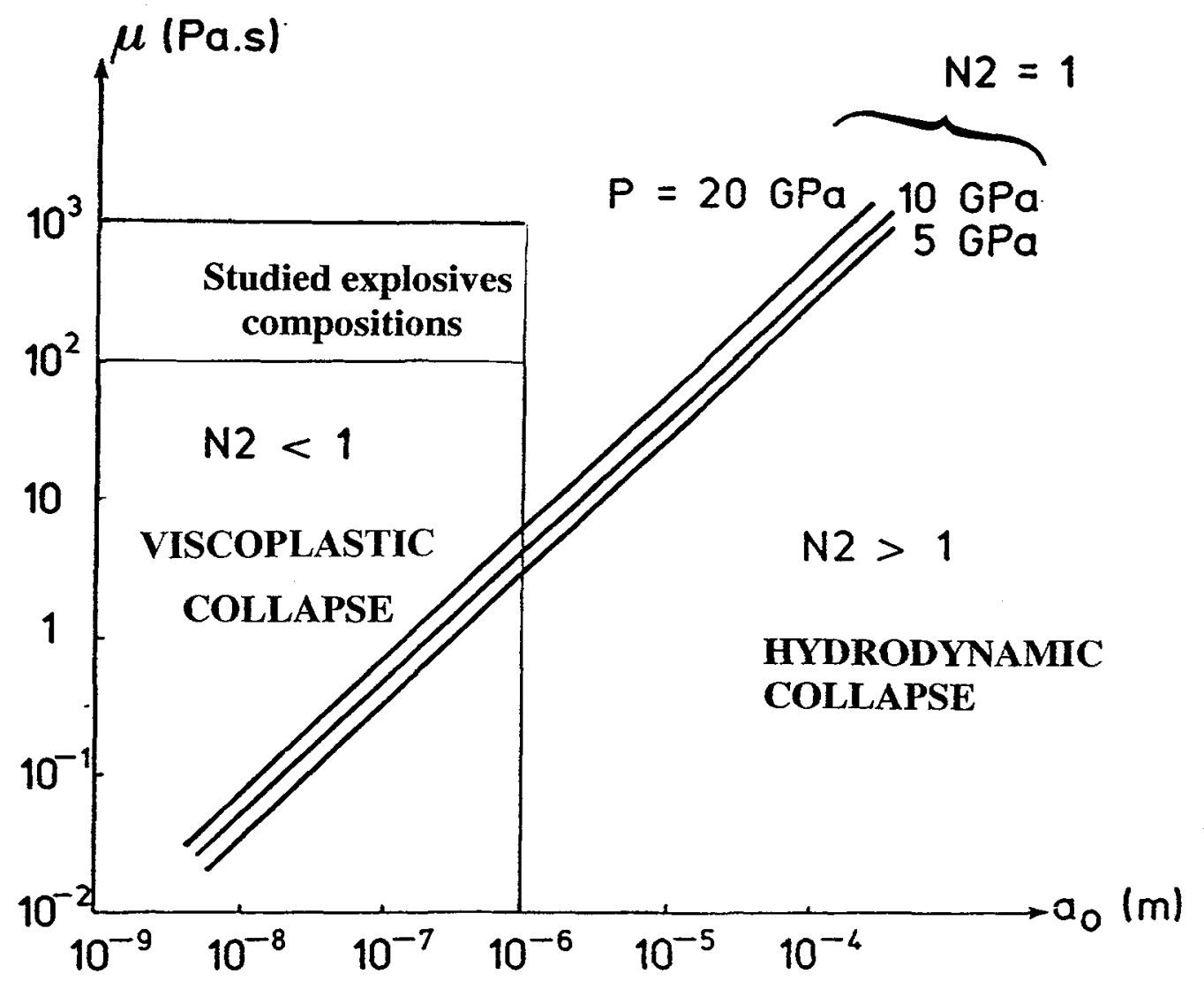

Figure 6 : ANALYSIS OF THE VISCOPLASTIC NATURE OF THE PORE COLLAPSE

Therefore, this analysis, added to the experimental data, shows that in pressed explosive compositions, the hot spots formation process is the result of the viscoplastic collapse of the pores included in the material. 


\section{3 - A HOT SPOTS FORMATION AND IGNITION MODEL [13]}

\subsection{The model}

The pores are described as hollow spheres. the comparison of the two typical times, one for the viscous collapse $\tau_{c}=\frac{4 \mu}{\mathrm{P}} \geq 10^{-7} \mathrm{~s}$, the other for the shock crossing through the pore $\tau_{\mathrm{s}}=\frac{2 . \mathrm{ao}_{0}}{\mathrm{U}} \leq 10^{-9} \mathrm{~s}$, shows that, at the beginning of the pore collapse, all the thermomechanical quantities are uniform all around the void. Therefore the implosion is spherical and initial values of pressure, density, and temperature are those induced by the shock in the medium surrounding the pore.

A program was written in order to compute the heating of the explosive around the collapsing void, and its time to ignition. Based on the same assumptions and equations than other published models[7] [8] [9], it calculates the evolution of a viscoplastic, heat-conducting, incompressible energetic material. The equations are :

$$
\begin{aligned}
& r^{3}-a^{3}=r^{3} 0-a^{3} 0 \\
& \rho \ddot{r}=\frac{\delta \sigma_{r}}{\delta r}-12 \mu \frac{\dot{r}}{r^{2}}+\frac{2 Y}{r} \\
& \rho C p \frac{\delta T}{\delta t}=\dot{C}+\dot{Q}+\dot{W}
\end{aligned}
$$

in which $\mathrm{Cp}$ heat capacity,

$$
\begin{array}{ll}
\text { I radius, } \\
\mathrm{T} \text { temperature, } \\
\mathrm{C} \text { thermal conduction term, } \\
\mathrm{Q} \text { heat released by chemical reaction term, } \\
\mathrm{W} \text { heat created by the viscoplastic work term, } \\
\sigma_{\mathrm{r}} \text { radial stress. }
\end{array}
$$

Therefore :

$$
\begin{aligned}
& \dot{W}=2 Y-\frac{\dot{r}}{r}+12 \mu\left(\frac{\dot{r}}{r}\right)^{2} \\
& Q=R Z Q \exp (-E / R T) \\
& C=\lambda\left[\frac{\delta T}{\delta r^{2}}+\frac{2}{r} \frac{\delta T}{\delta r}\right]
\end{aligned}
$$

in which $\mathrm{R}$ ideal gas constant,

$\mathrm{Z}$ frequency factor,

Q heat of decomposition,

E activation energy,

$\lambda$ thermal conductivity.

All the parameters of these equations have a physical meaning, and can be determined with a good accuracy but the viscosity. This last parameter can be calibrated by using the hot spots model together with pressure history curves measured with embedded manganin gauges in shocked explosives samples 


\subsection{Determination of the viscosity}

The experimental set-up is presented in Figure 7. The velocity of the projectile is chosen in order to have the needed shock pressure in the explosive. The pressure versus time curves are measured in the shocked explosive sample (Figure 8 ). If the shock pressure is not too high (in the shown example, $9 \mathrm{GPa}$ in the TATB composition T2), the curve presents two parts : a plateau followed by an increase of the pressure. The physical meaning of these two parts may be : the initiation of the hot spots followed by an increase of the pressure generated by the decomposition gases.

The extrapolation, up to the zero depth, of the curve which represents the duration of the plateau as a function of the depth of measurement, gives the value of the initiation time of the hot spots for the given pressure. This ignition time was determined for several shock pressures. The comparison of these experimental values with those obtained with the numerical model leads to a given value of the viscosity.

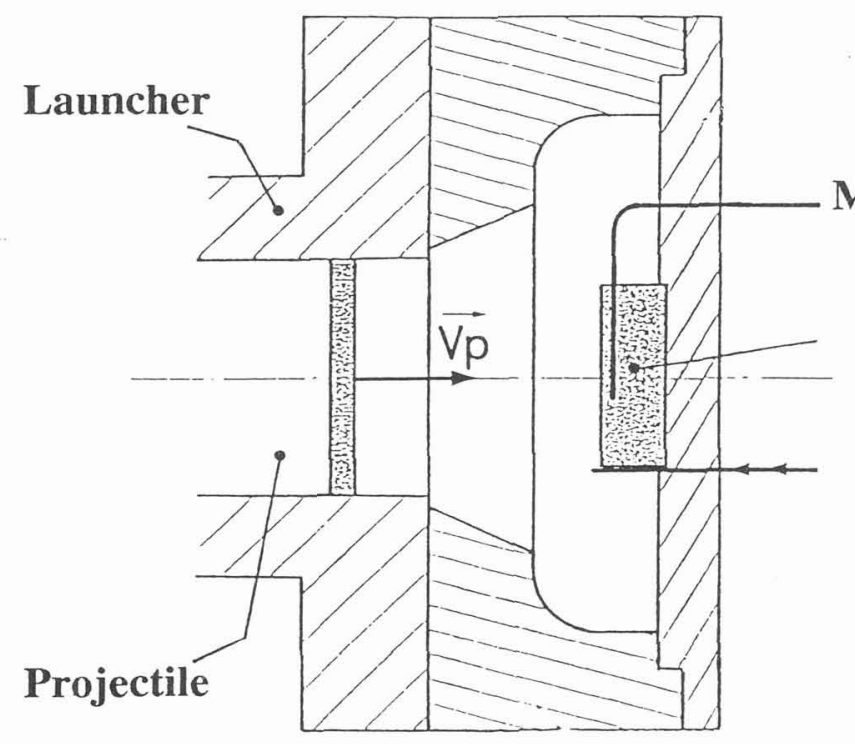

Manganin gauge $\longrightarrow \mathbf{P}(\mathrm{t})$

Explosive sample

$\mathrm{DLI} \longrightarrow \mathrm{Vp}$ 


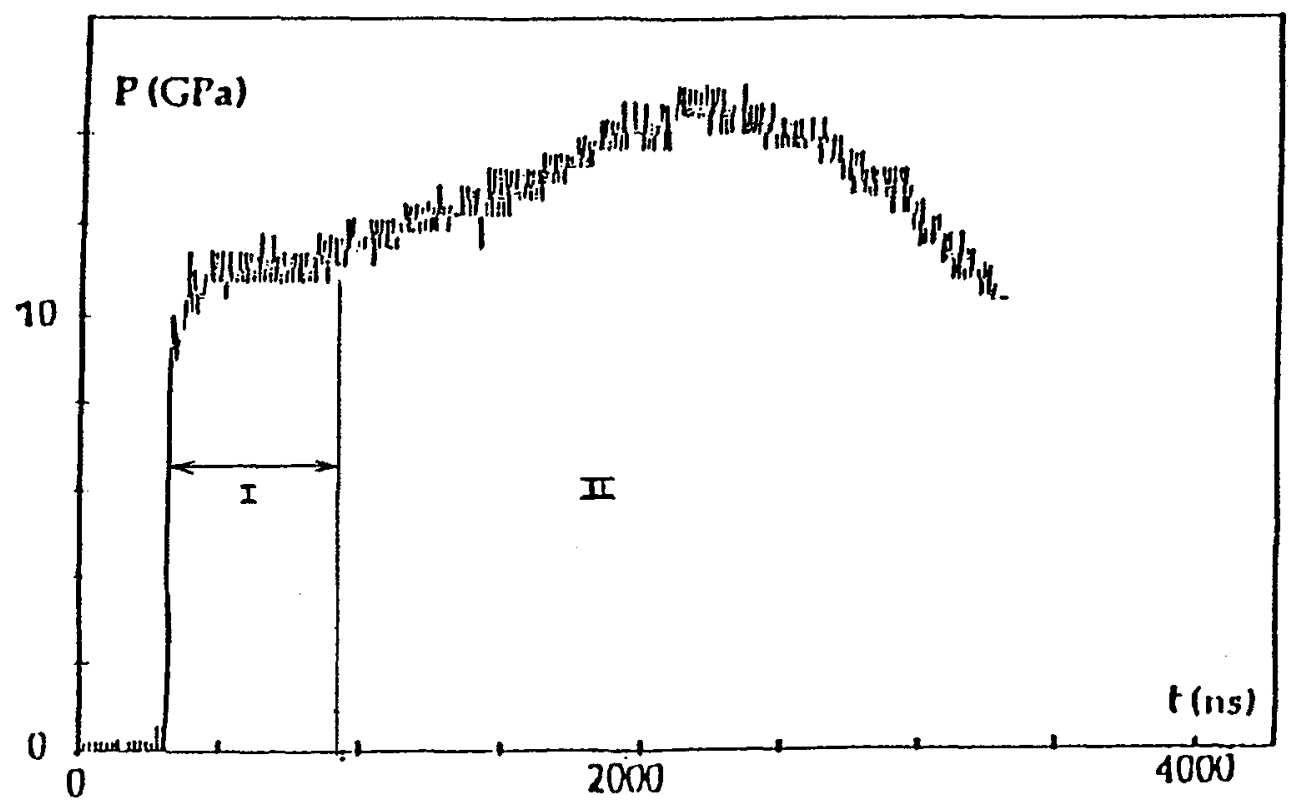

Figure 8 - TYPICAL PRESSURE VS TIME CURVE

But the so calibrated model is not able to simulate other experiments, like double-shocks impacts. In fact, the duration of the first plateau is not only the ignition time of the hot spots ; it includes also the time required to obtain a sufficient amount of gases which leads to a pressure increase in the explosive.

With the same experimental set-up, it is possible to determine the pressure threshold of shock initiation. Using the hot spots model with a given viscosity, it appears that, the larger the pore, the easier the initiation (Figure 9). Therefore, for a given shock pressure, the initiation time of the composition is the initiation time of the largest voids. The smaller pores, if initiated by the shock, modify the energy release history behind the shock, but have no influence on the first reactions initiation. The model used with the largest voids diameter and the good value of the viscosity will reproduce these threshold values. 


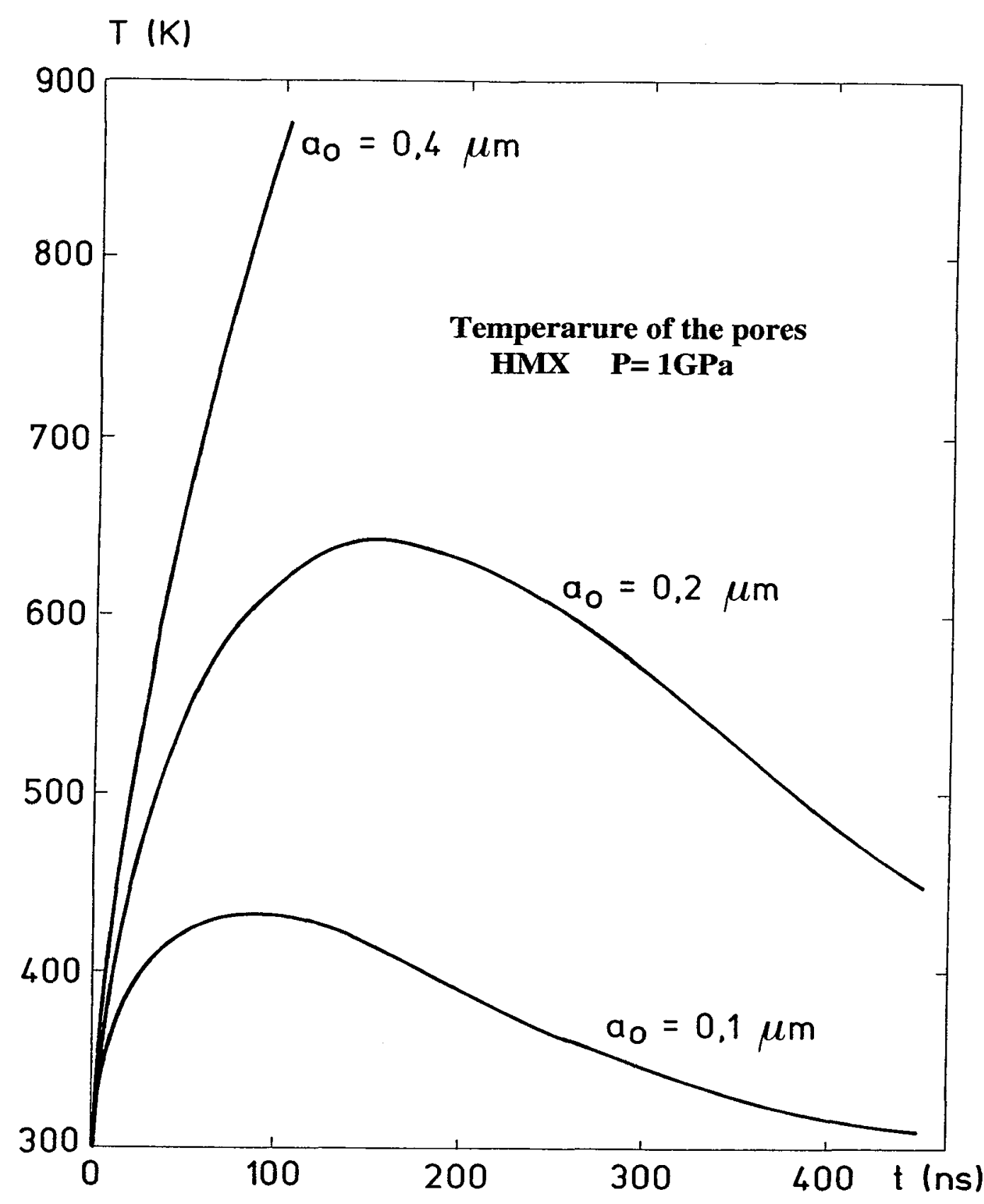

Figure 9 - TEMPERATURE VS TIME IN THE MEDIUM AROUND VOIDS OF SEVERAL INITIAL RADII 
The results obtained on two explosives compositions, X1 and T2 (defined in Table 2) are presented. From the pressure measurements reported in Figures 10 and 11 , the threshold pressure for $\mathrm{X} 1$ and $\mathrm{T} 2$ are respectively 1 and $4 \mathrm{GPa}$. The viscosity of HMX and TATB deduced from these values and the viscosity of the TATB is about five times the HMX one.

\begin{tabular}{|c|c|c|c|}
\hline Coniposition & X. & T2 & 181: \\
\hline HMX wt \% & $\begin{array}{c}96 \\
0-600\end{array}$ & 0 & $\begin{array}{c}45 \\
0-100\end{array}$ \\
\hline $\begin{array}{c}\text { TATB wt } \% \\
\text { grain size }(\mu \mathrm{m})\end{array}$ & 0 & 97 & 52 \\
\hline Inert binder wt $\%$ & 4 & 3 & 3 \\
\hline $\begin{array}{l}\text { Porosity and pores radii } \\
\qquad(\mu \mathrm{m})\end{array}$ & $\begin{array}{c}1.7 \% \\
a_{0} \leq 0.5\end{array}$ & $\begin{array}{c}2.3 \% \\
a_{0} \leq 0.5\end{array}$ & $\begin{array}{c}0.5 \% \\
\text { intergranular } \\
\mathrm{a}_{0} \leq 0.2 \\
1.5 \% \text { in the } \\
\text { TATB } \\
\mathrm{a}_{0} \leq 0.5\end{array}$ \\
\hline
\end{tabular}

Table 2 - EXPLOSIVES MICROSTRUCTURE

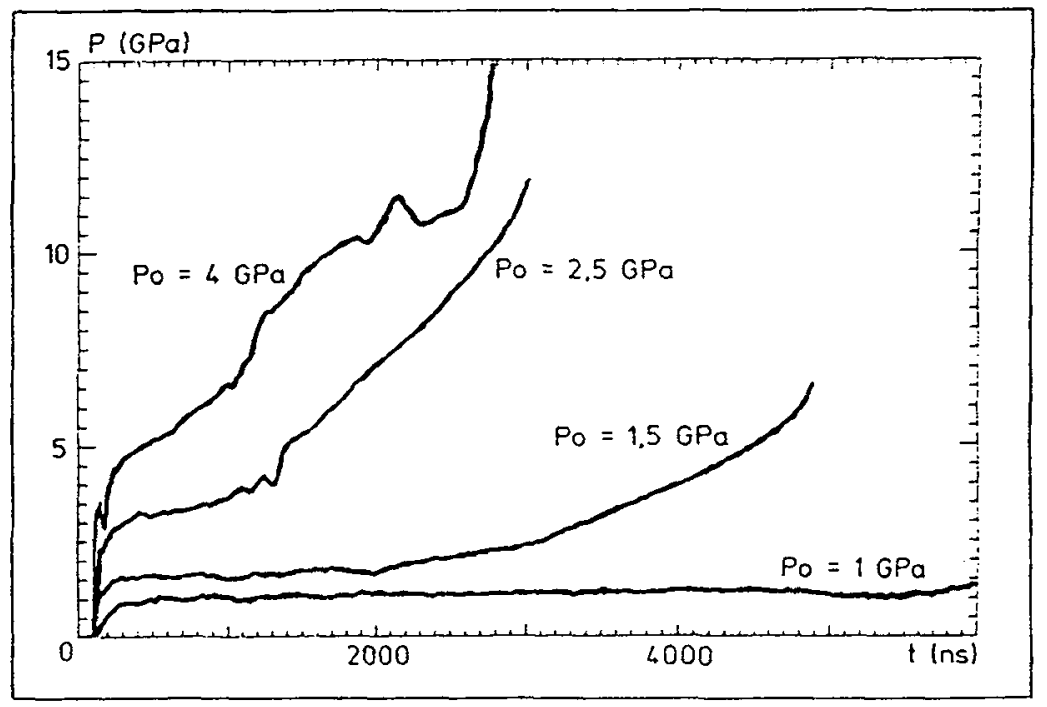

Figure 10 - PRESSURE VS TIME IN XI COMIPOSITION 


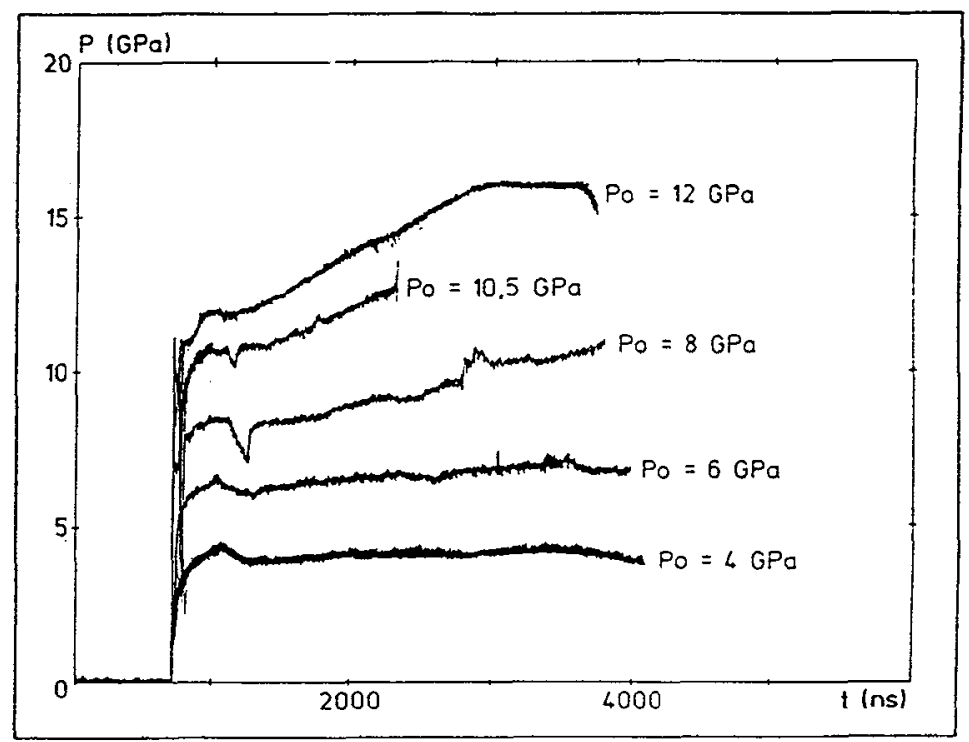

Figure 11 - PRESSURE VS TIME IN T2 COMPOSITION

FOR SEVERAL INPUT PRESSURES

\subsection{An analytical model}

We developed a simplified hot spots model, easier to use in a code and which gives the same results about the evolution of the microvoids (radius, temperature) that those obtained previously, with the reference numerical model.

3.3.1-Motion equation: The evolution of the radius of the pore is governed by the equation :

$-\rho \mathrm{a} a=P-P y+4 \mu \frac{\mathrm{a}}{\mathrm{a}}+1.5 \rho \mathrm{a}^{2}$

with : a : pore radius,

$\mathrm{P}_{\mathrm{Y}}:-2 / 3 \mathrm{Y}$ In $\varnothing$,

$\varnothing$ : porosity.

The asymptotic solution of this equation is :

$a=a_{0} \exp \left[\int_{0}^{t}-\frac{P-P_{y}}{4 \mu} d t\right]$

We use this formula for $a(t)$ in the simplified model because it leads to a very good agreement with the results of the reference model (Figure 12). 


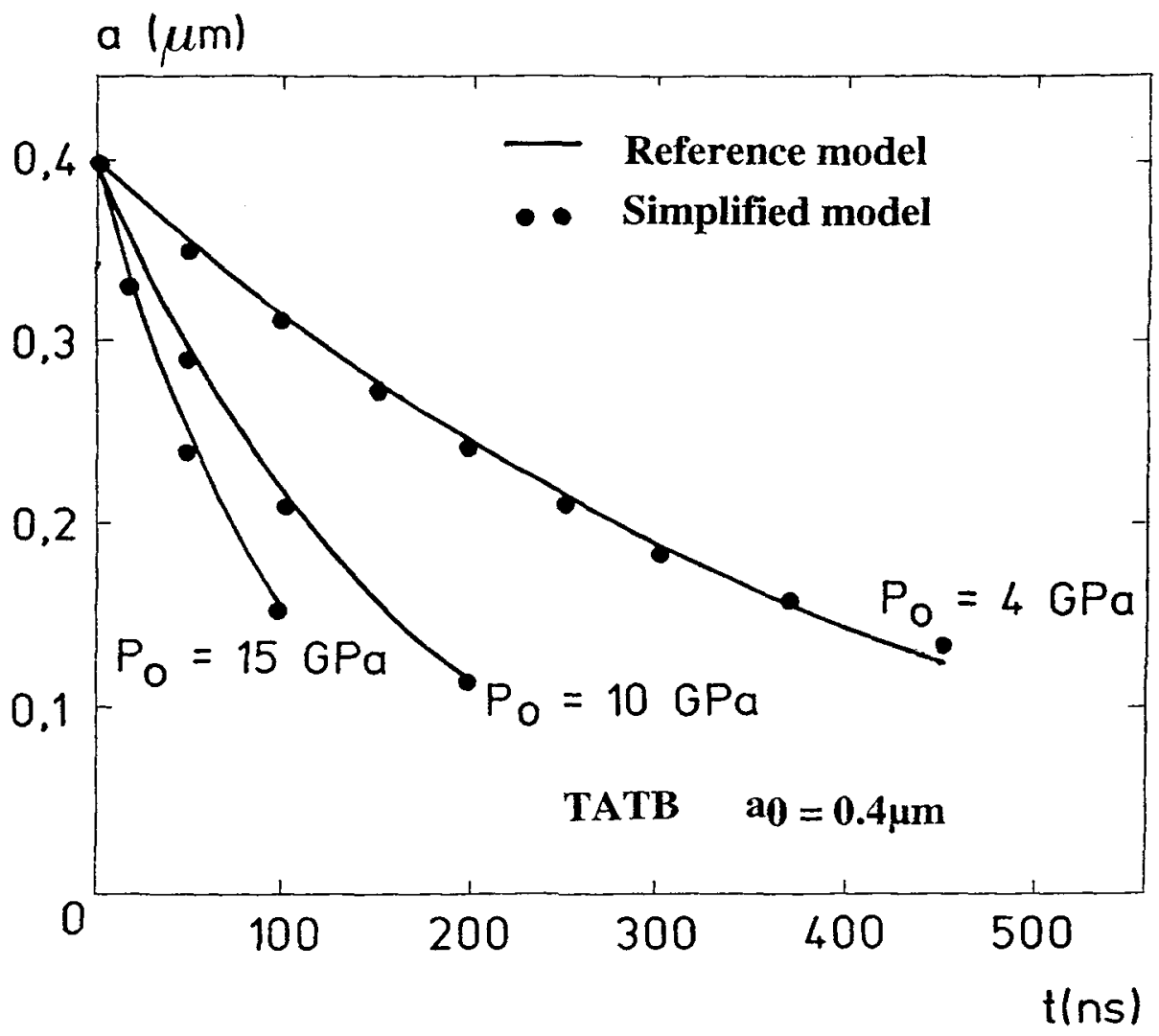

Figure 12 - COMPARISON OF SIMPLIFIED MODEL AND REFERENCE MODEL

3.3.2 Viscoplastic heating and thermal conduction :The pore wall temperature increase, due to the viscoplastic strains of the explosive, is given by

$d \theta_{v p}=\left[\frac{12 \mu}{\rho C_{p}} \frac{\dot{a}^{2}}{a^{2}}-\frac{2 Y}{\rho C_{p}} \frac{\dot{a}}{a}\right] d t$,

where $\mathrm{a}$ is given by the motion asymptotic solution.

The cooling of the material, resulting from the thermal conduction, is calculated with a simplified analytical model based on an approximated heat balance in a spherical geometry (Figure 13). 


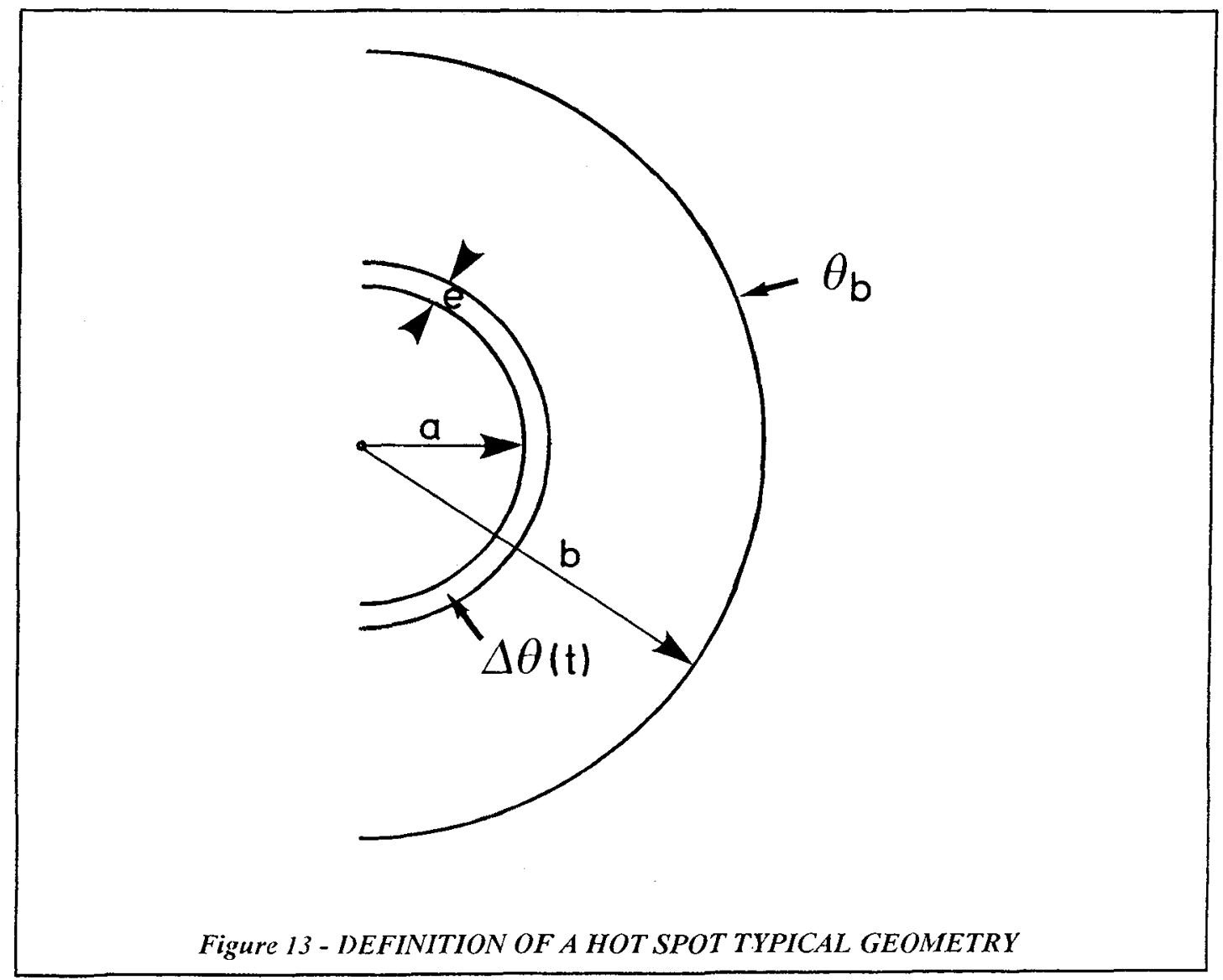

We calculate the temperature (assumed uniform) in a thin shell (thickness : e) of explosive surrounding the void. During $d t$, this temperature increases by $d \theta_{v p}$ as a result of viscoplastic heating, and the approximated heat balance is given by :

$\frac{4 \pi \lambda \mathrm{ab}}{b-a}\left(\theta(t)+d \theta_{v p}-\theta_{0}\right) d t=4 \pi \rho C_{p} a^{2} f a_{0} d \theta_{c}$

where $d \theta_{c}$ is the cooling due to thermal conduction. Then, the pore wall temperature is given by :

$\theta(t+d t)=\theta(t)+d \theta_{v p}-d \theta_{c}+d \theta_{d}$

$\mathrm{d} \theta_{\mathrm{d}}$ is the increase in temperature produced by the explosive decomposition, and is calculated with a simple zero order Arrhenius kinetics.

The thickness of the shell, $e$, is equal to $f_{0}$, where $f$ is a function of the non-dimensional variable :

$x=\frac{\rho C_{p}}{\lambda} \frac{a^{2} \dot{a}}{a_{0}}$

This function is determined in order to fit the results delivered by the reference hot spot model, as shown in Figure 14. 


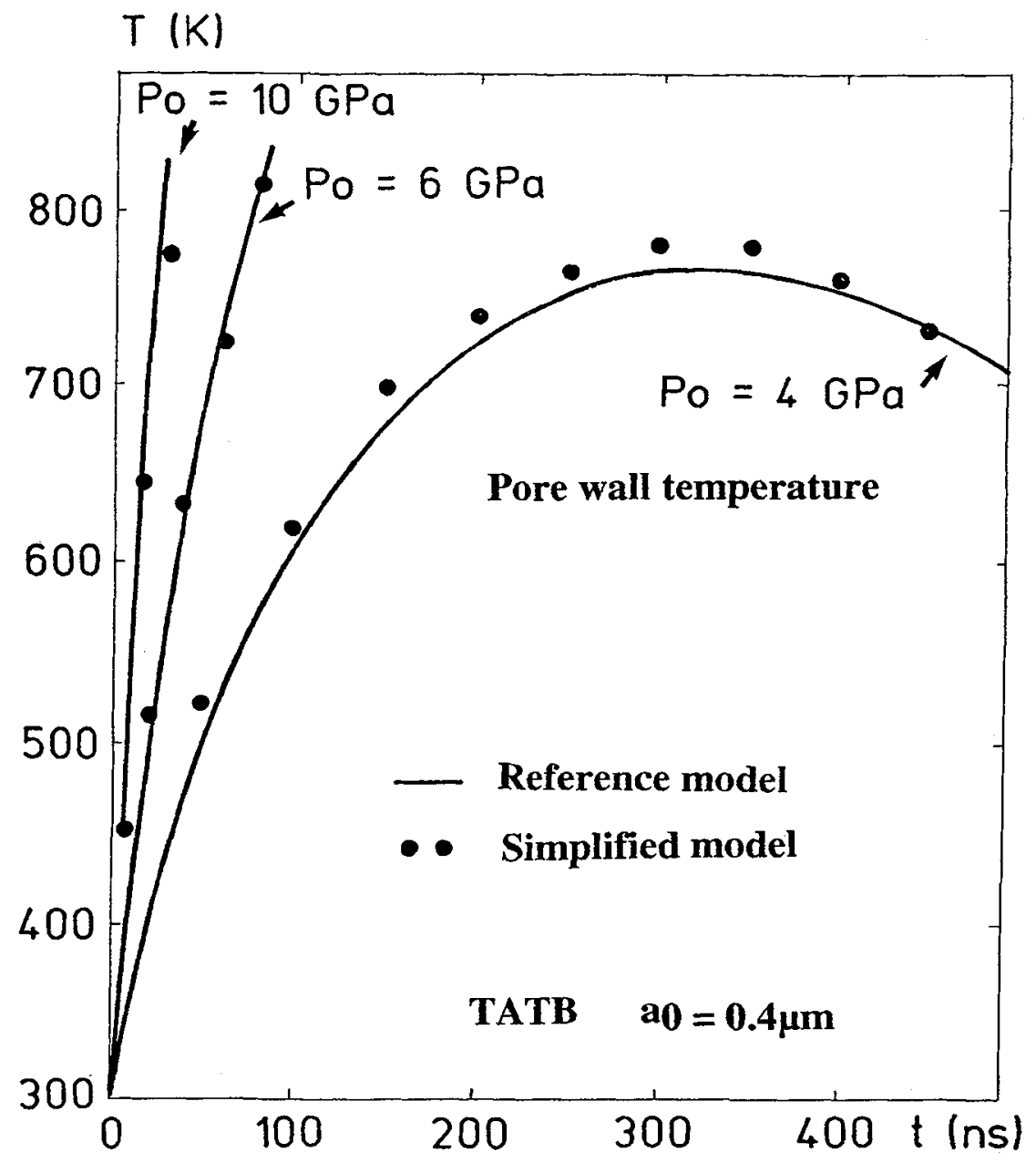

Figure 14 - PORE WALL TEMPERATURE CALCULATED WITH THE SIMPLIFIED MODEL AND THE REFERENCE ONE

\subsection{Hot spots in cast explosive compositions :}

The porosity is generally very weak in cast compositions. Then, the origin of hot spots cannot be explained exactly as previously.

However a very close approach can be done, the same mechanism can be invoked and the same models apply with slight modifications. 
Cast compositions are characterized by high percentage of binder. Thus a schematic representation of the microstructure of these compositions, suitable for modelling, can then be "large" cavities surrounded by explosive and filled with binder. Microscopic observation can give the characteristic size of these cavities and the model must be modified to take into account the compressibility of the binder. This can be done by taking into account, in the motion equation, a cavity internal pressure opposite to the shock pressure and depending on time (degree of collapse) and on the properties of the binder. In this case, the more compressive the binder, the easier the collapse of the cavity.

As a result of this, compositions with compressive binder should be more sensitive.

\section{4 - APPLICATIONS}

\subsection{Initiation study of a mixed TATB-HMX composition [14] [15]}

We studied the shock initiation of composition TX1 (see Table 2). The experimental pressure threshold measured for TXl is $2.5 \mathrm{GPa}$ (Figure 15) The TATB is not initiated by the shock wave, at this pressure (Figure 11) and the composition is ignited by the HMX. The hot spots model with the viscosity value determined for $\mathrm{X} 1$ and $1 \mu \mathrm{m}$ pores diameter predicts the $2.5 \mathrm{GPa}$ value for the threshold pressure of TX1 in which the larger pores are only $0.4 \mu \mathrm{m}$ in diameter (Figure 16).

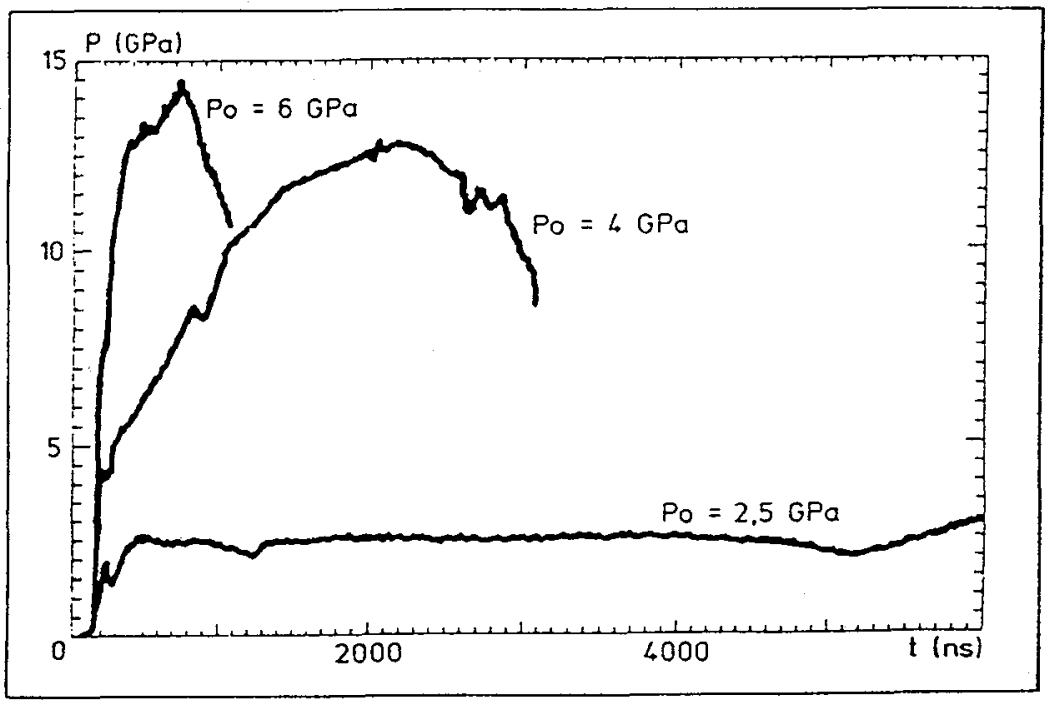

Figure 15 - PRESSURE VS TIME IN TXI COMPOSITION FOR SEVERAL INPUT PRESSURES 


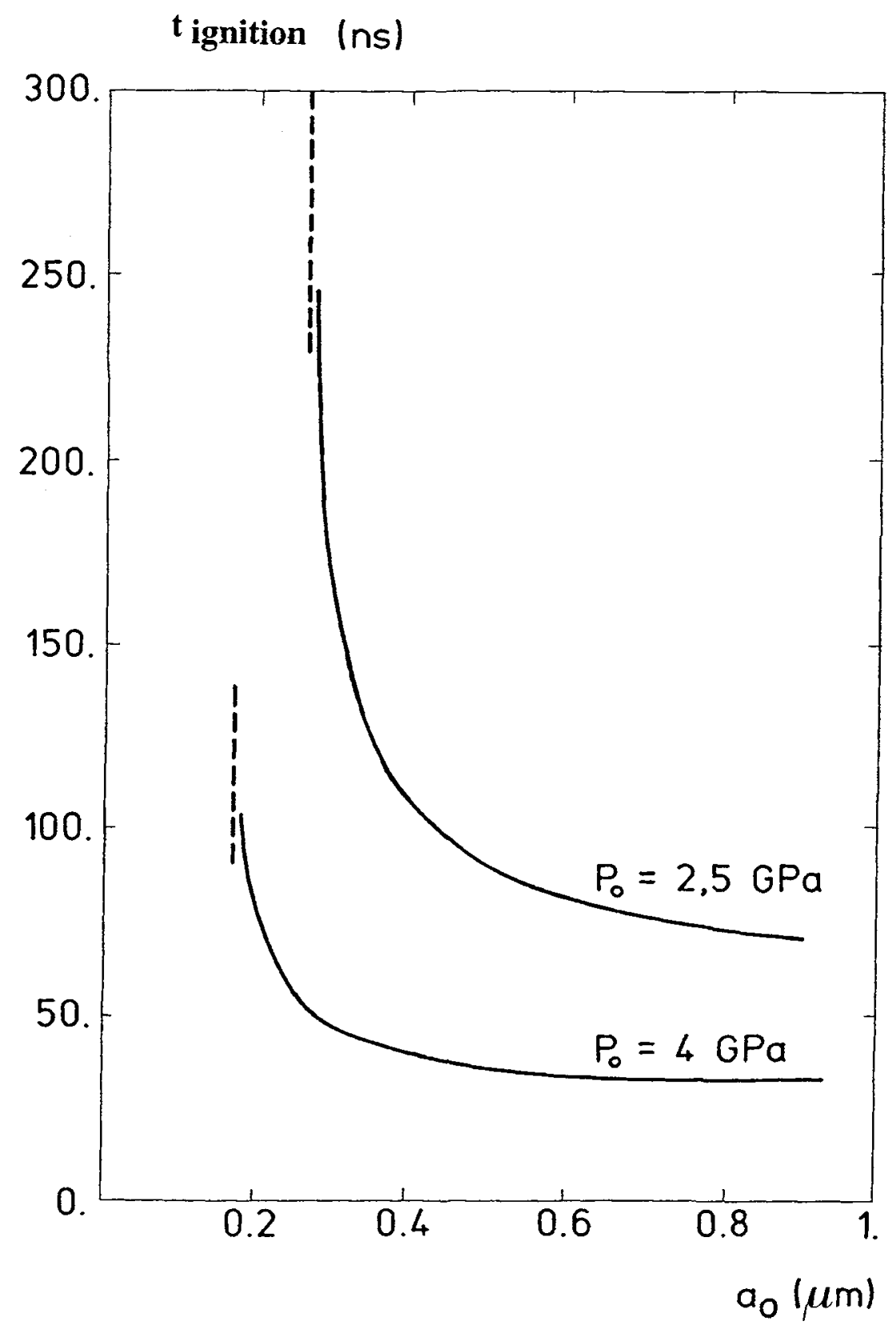

Figure 16 - IGNITION TIME OF INTERGRANULAR HOT SPOTS 


\subsection{ANALYSIS OF DOUBLE SHOCKS ON HMX, TATB, AND HMX/TATB COMPOSITIONS}

If an explosive sample is subjected to a low pressure shock, the pores collapse with a slow heating and, due to cooling by heat conduction, do not ignite. The pore collapse duration is a function of shock pressure, pore diameter and explosive viscosity.

If the explosive is subjected to a second shock (Figure 17) of a higher pressure, even higher than the threshold pressure previously determined, it can be not initiated. This desensitization phenomenon depends on first shock pressure and duration, and on second shock pressure.

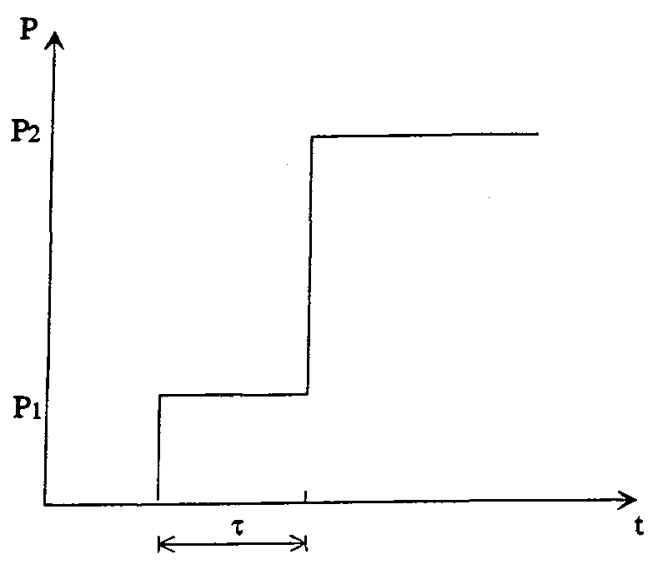

Figure 17 - TYPICAL DOUBLE-SHOCK PROFILE

For example, for $\mathrm{X} 1$ composition, if $\mathrm{P} 1=0.5 \mathrm{GPa}$ and $\mathrm{P} 2=1.4 \mathrm{GPa}$, comparisons with the hot spots model show that for $\tau>0.2 \mu \mathrm{s}$, the explosive is desensitized. This numerical value is in good agreement with experimental results (Figure 18).

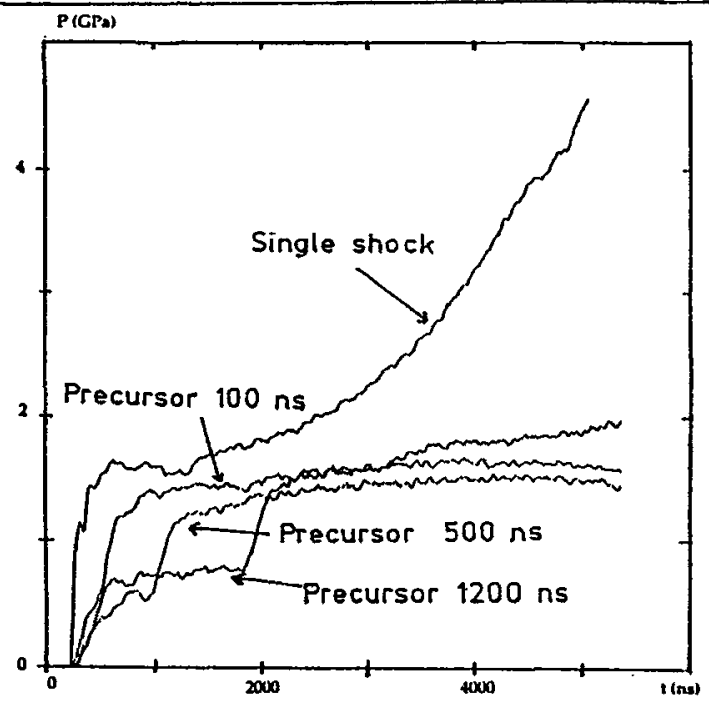


A TATB composition is more difficult to desensitize, because of its higher viscosity. But, as shown in Figure 19, the same phenomenon can be obtained.

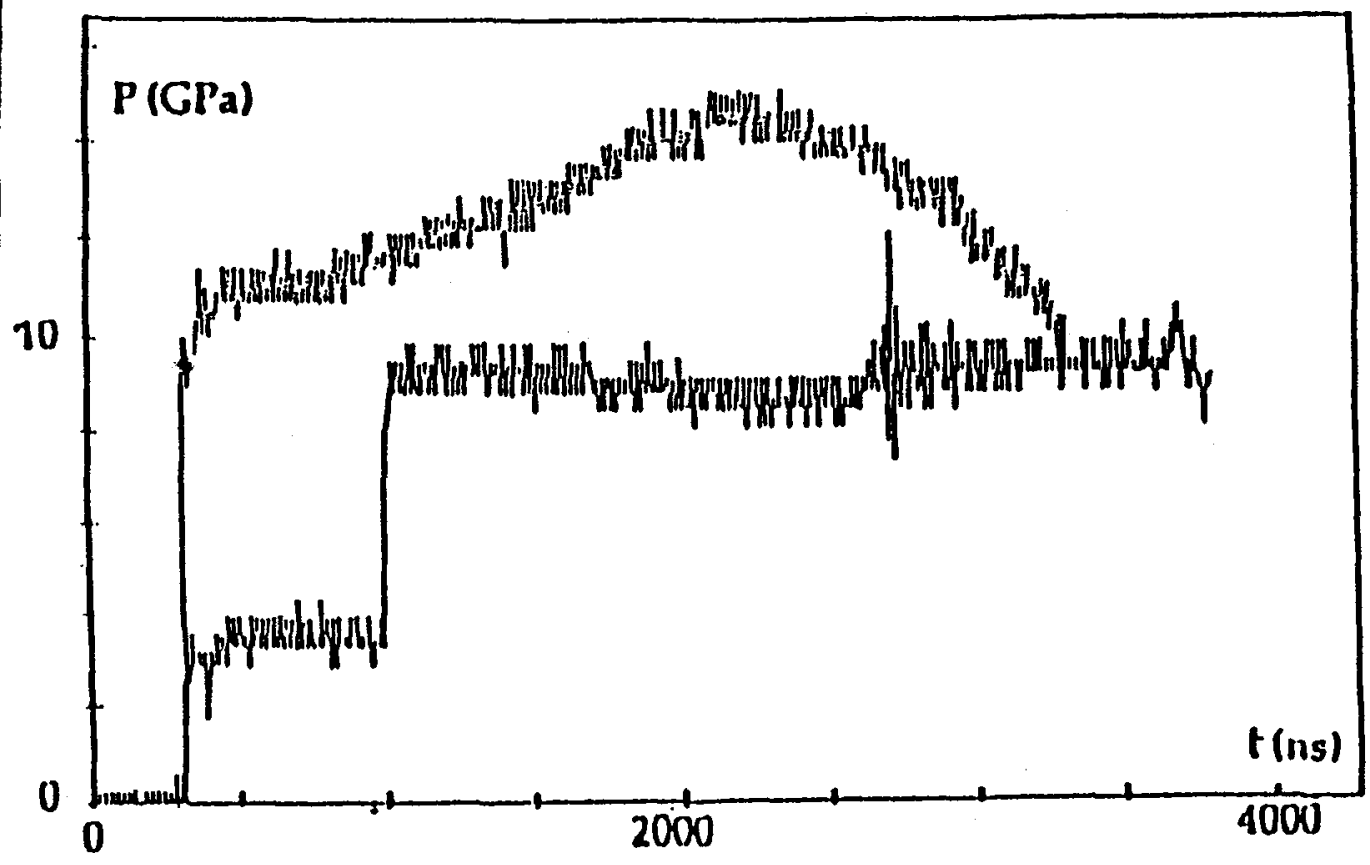

Figure 19 - PRESSURE VS TIME IN T2 COMPOSITION SUBJECTED TO DOUBLE SHOCKS

For a HMX/TATB composition, the initiation process is more complex. Experimental results are presented in Figure 20. In this example, $\mathrm{P} 1=1.6 \mathrm{GPa}$, lower than the initiation threshold pressure of the composition. At this shock pressure, the pores directly connected with the $\operatorname{HMX}\left(\mathrm{a}_{0}=0.2 \mu \mathrm{m}\right)$ are rapidly closed and no hot spot will be created in the HMX by the P2 $=4$. GPa shock. The TATB powder is the same than the one used in T2, with $1 \mu \mathrm{m}$ in diameter pores. As the TATB viscosity is greater than the HMX one, a longer time is required to get the closure of the pores. Therefore, if the duration of the precursor shock is less than $500 \mathrm{~ns}$, the $4 \mathrm{GPa}$ shock induces a heating of the TATB around the voids $\left(800^{\circ} \mathrm{C}\right)$. The TATB cannot be initiated, but, by conduction of the thermal energy to an adjoining HMX grain, the TXl composition is initiated. 


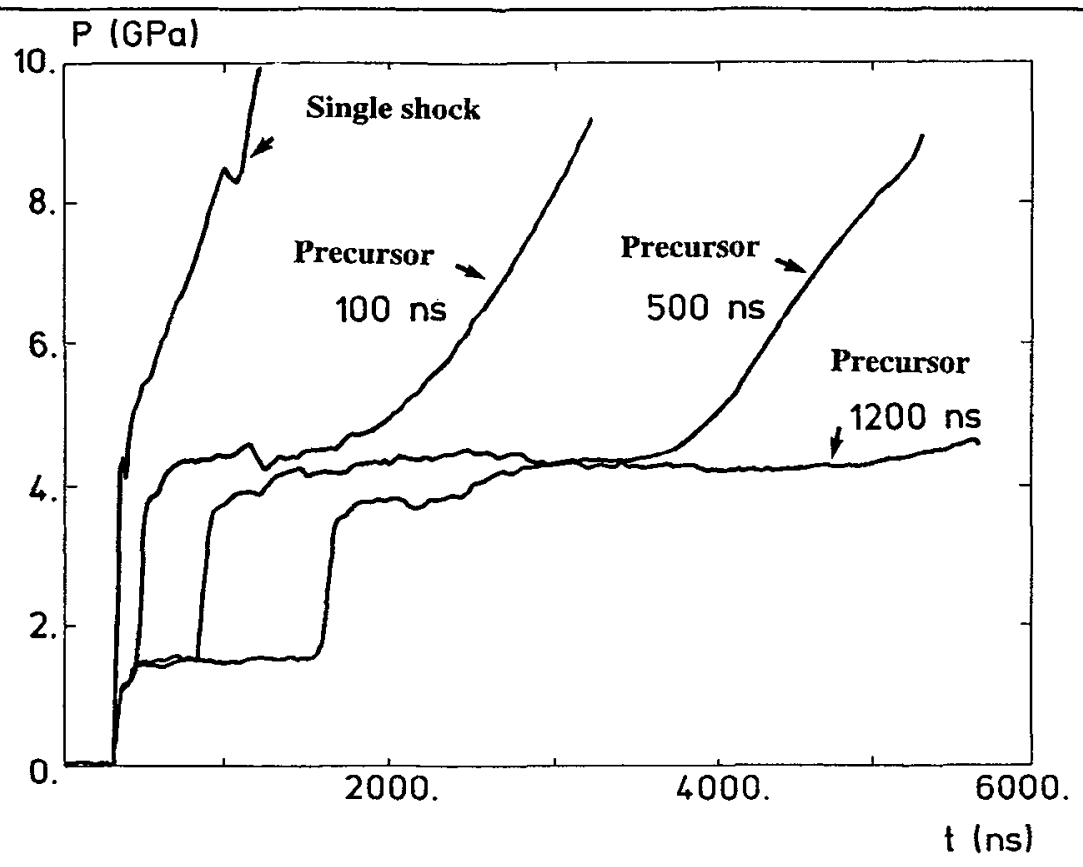

Figure 20 - PRESSURE VS TIME IN TXI COMPOSITION SUBJECTED TO DOUBLE SHOCKS

\subsection{Development of a physical kinetics [15] [16]}

The study of the behavior of explosive devices subjected to mechanical stimuli requires numerical modelisation of the shock-to-detonation transition. Several models, able to compute the shock initiation of heterogeneous explosives, were developed in different laboratories. The most famous and used are the Ignition and Growth Model [17] [18], the Forest-Fire Rate and the Explicit Hot Spot Model [19] [20]. These models are efficient tools but their empirical formulations and, in some cases, the important number of parameters needed, limit their applications.

In another connection, all the laboratories working about the formulation of explosive compositions are looking for insensitive high explosives. A kinetics of decomposition of the explosive, which takes into account the microstructure of the explosive composition, would help the researchers in their choices.

The shock-to-detonation transition is the result of two basic phenomena :

- hot spots formation and ignition,

- explosive burning under high pressure.

As a result, a good kinetic able to simulate all the events involved in the SDT process must be composed of two physical models well-adapted to the description of these two basic phenomena.

The AMORC kinetics has been developed using the previously described analytical hot spots model (see 3.3) and an efficient grain burning law.

This kinetics is able to describe all the phenomena involved in shock initiation like :

- SDT for high and low (induction time) incident pressures.

- Explosive desensitization by small pressure precursor or pressure ramp wave.

- Propagation of the detonation, interactions with inert materials.

- Influence of the temperature on the SDT.

- Influence of the microstructure (porosity, grain size, grain morphology)

- Mixed compositions reactive behavior 
4.3.1 Explosive grain burning [21] [22] : The influence of grain size on the microstructural burning is well known. Fine grains generally burn faster than coarse ones. In addition, the importance of grain morphology on the decomposition phenomena was demonstrated [21] [22]. The assumed mechanism based on these works is composed of three phases: hot-spots ignition on the surface, grain surface growth, and grain burning.

The association of a powder morphology analysis with a grain mathematical erosion method leads to an evolution of the yield, $p / S$ (perimeter/surface of the grains) characteristic of the real powder. As an example, for the TATB powder used in our TATB compositions, the calculated evolution of $\mathrm{p} / \mathrm{S}$ as a function of the unburned mass fraction $W$ is plotted in Figure 21.

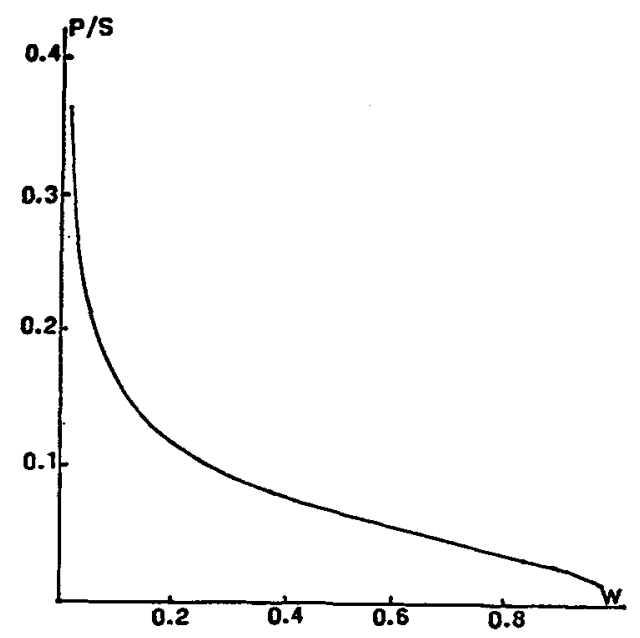

Figure 21 - EVOLUTION OF GRAIN MORPHOLOGY DURING THE DECOMPOSITION

4.3.2 The AMORC kinetics [15][16] : As mentioned previously, the AMORC kinetics is the association of the hot spots model with the grain burning law. The decomposition term of the kinetics is given by :

$-\frac{\mathrm{l}}{\mathrm{W}} \frac{\mathrm{dW}}{\mathrm{dt}}=\mathrm{F}(\mathrm{N}) \cdot \frac{\mathrm{p}}{\mathrm{S}} \cdot \mathrm{V}_{\mathrm{c}}(\mathrm{P})$

where: $\quad-F(N)$ is a function of the number of hot spots, $N$, calculated by the hot spots model, in which a pore size distribution is introduced.

$-V_{C}(P)$ is the pressure dependent burning velocity, measured in strand burner tests.

4.3.3 Validation of the AMTORC kinetics: The AMORC kinetics is implemented in a one dimensional hydrodynamic code. As seen previously, the hot spots model is able to calculate the threshold initiation shock pressure and to predict the desensitization of the explosive by a precursor shock. The kinetics must reproduce the pressure versus time curves measured at several depths in shocked explosive samples.

In Figure 22 are plotted the profiles of pressure as a function of time, measured with manganin gauges in a TATB composition (T2) for an initial sustained shock of $11 \mathrm{GPa}$, and calculated with the AMORC kinetics. Figure 23 presents the comparison between measurements and calculations of pressure profiles at $5 \mathrm{~mm}$ depth in the explosive, for different initial shock pressures.

A good agreement is obtained in all cases. The run distance to detonation as a function of the input pressure was also calculated and agreed well with experiments. 


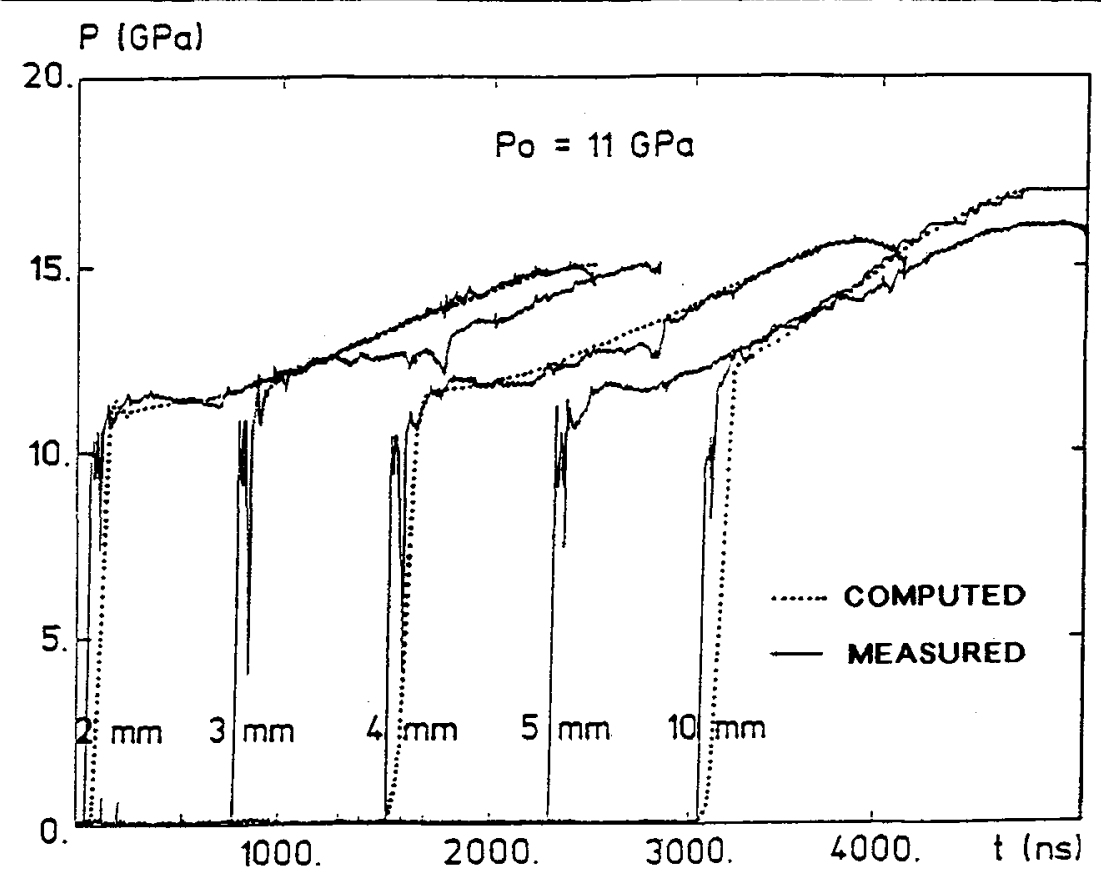

$P$ (GPa)

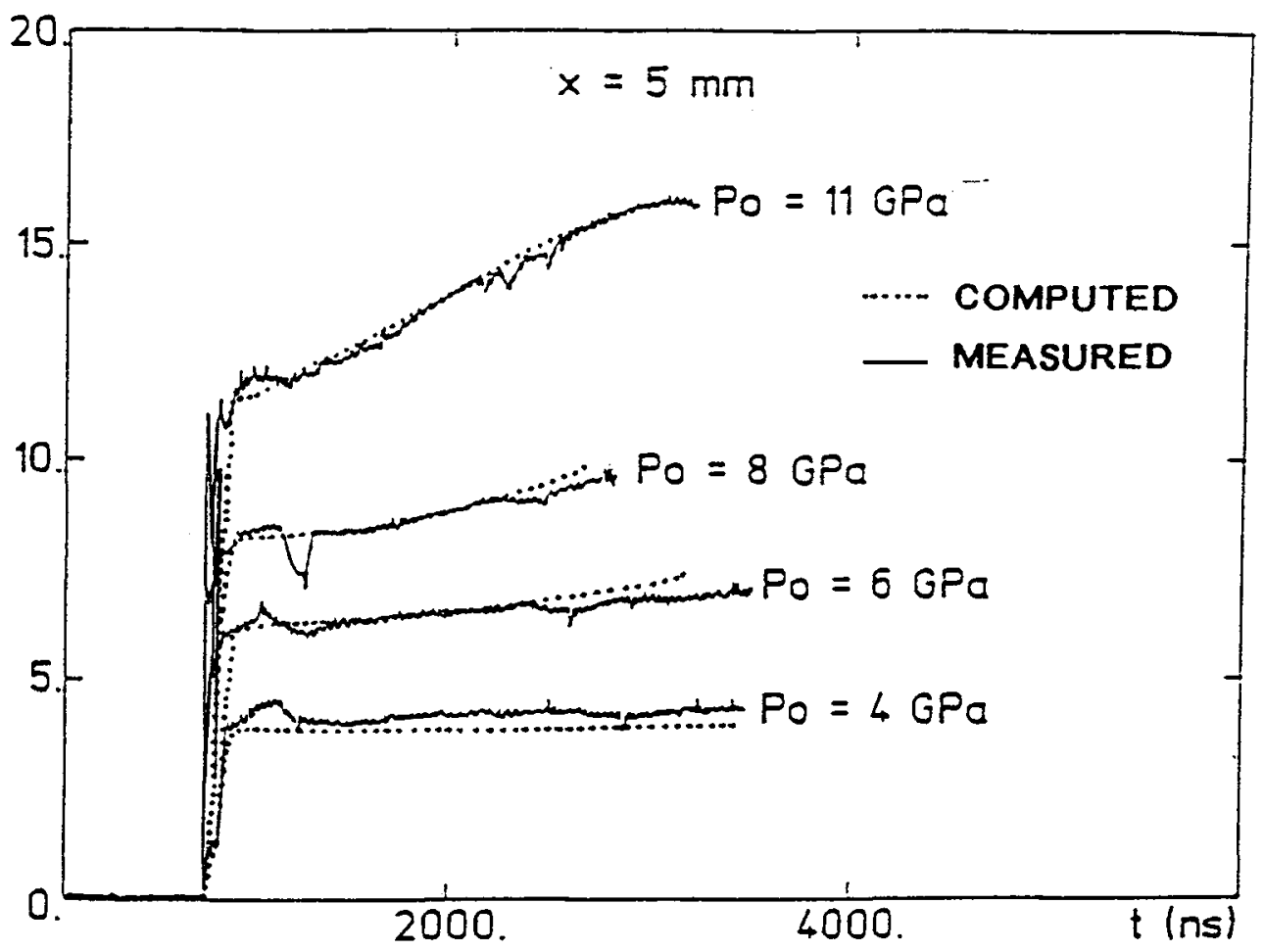

Figures 22 and 23 : COMPARISON BETWEEN 
As shown in Figure 24, computations with AMORC reproduce the desensitization of the explosive by a precursor shock.

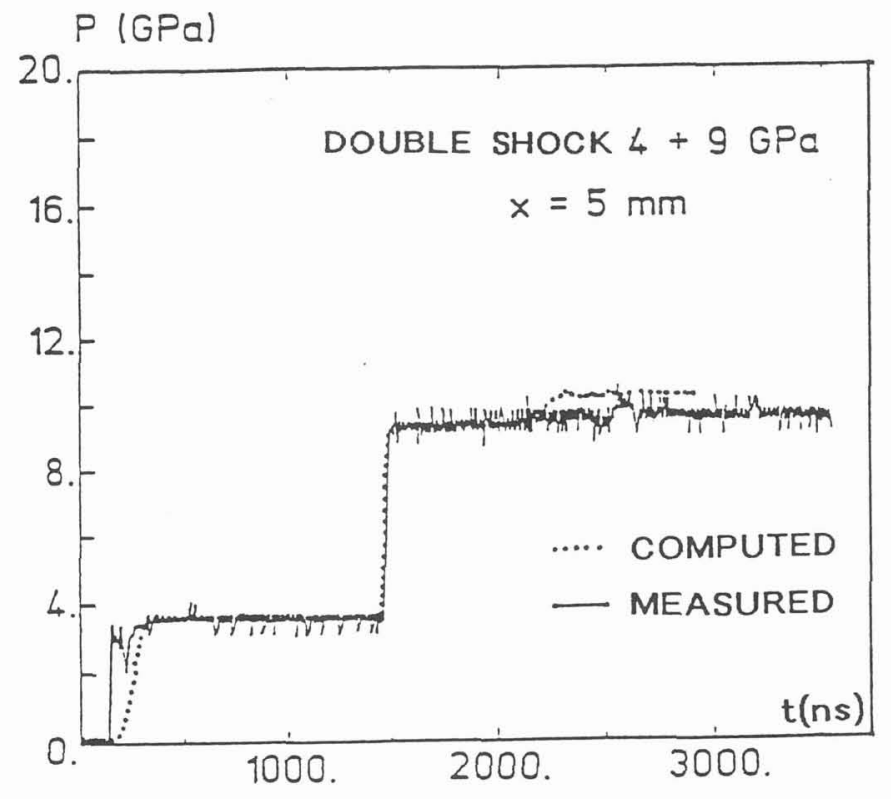

Figure 24 - EXAMPLE OF DESENSITIZATION OF TATB COMPOSITION
BY PRESHOCKING

4.3.4 New applications :In the two parts of the kinetics, the microstructure of the explosive is explicitly introduced, and the temperature of the medium is taken into account to determine the ignition of the hot spots. The physical description of the initiation process allows preliminary numerical studies of new explosive compositions, in which the porosity, the grain size or the grain morphology are modified. The explicit calculation of the temperature in the ignition process has an important application in safety studies. Two examples are shown now as an illustration of the AMORC capabilities.

Influence of the initial temperature :

On Figure 25, are plotted the pressure profiles calculated for $\mathrm{T} 2$ composition at $300 \mathrm{~K}$ or preheated at $500 \mathrm{~K}$ and subjected to the same shock. These results exhibit a small but significant sensitization of the explosive when it is heated before impacted.

Influence of the microstructure :

Let $\mathrm{C} 1, \mathrm{C} 2$ and $\mathrm{C} 3$ be three TATB compositions composed of spherical grains of three different diameters. These three compositions are defined in Table 1 . The smaller the grain size, the smaller the pores. The pressure calculated after a $5 \mathrm{~mm}$ propagation of the shock in the explosive samples for a 10 GPa sustained shock are reported in Figure 26. 


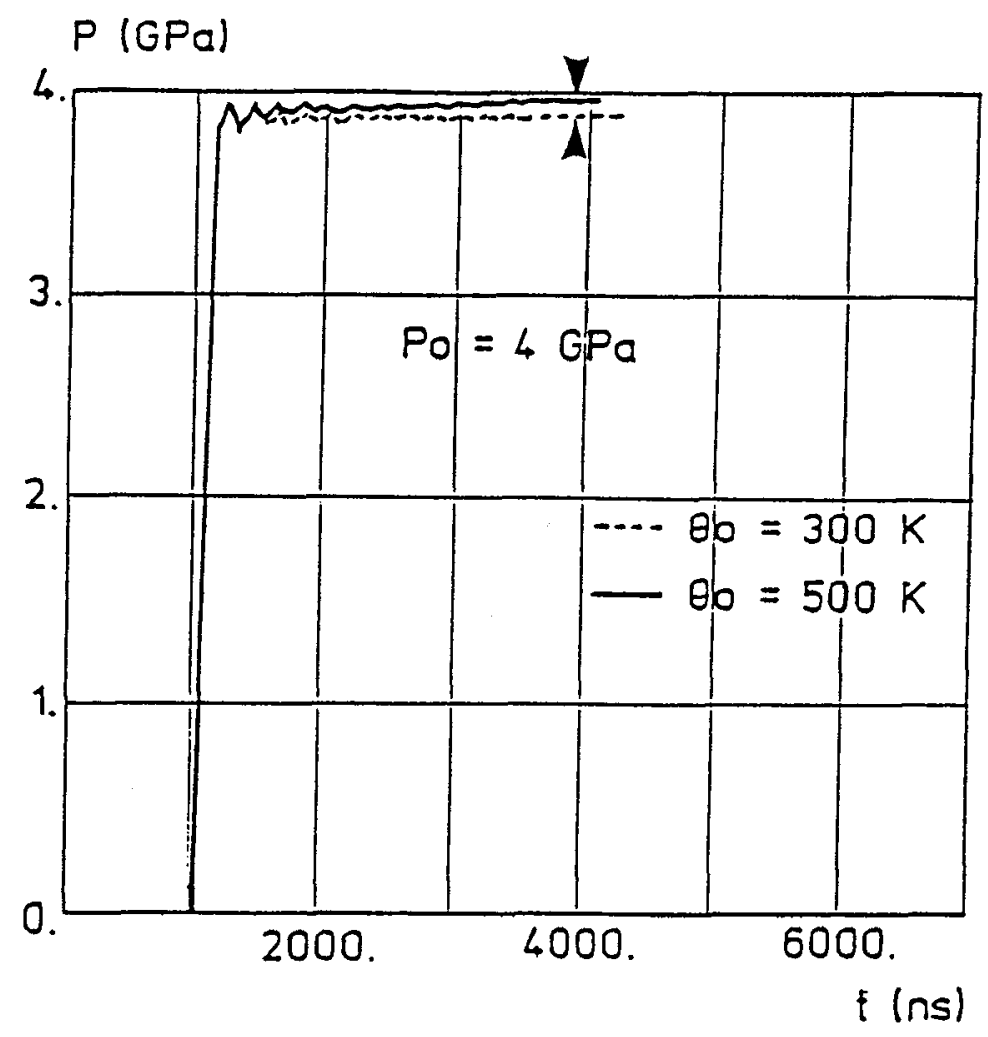

Figure 25 - EFFECT OF THE TEMPERATURE ON THE SENSITIVITY OF EXPLOSIVE COMPOSITIONS

\begin{tabular}{|c|c|c|}
\hline & Grarns orameter & Pores radius \\
\hline $\mathrm{Cl}$ & 50 & 0.4 \\
\hline $\mathrm{C} 2$ & 10 & 0.2 \\
\hline C3 & 1 & 0.1 \\
\hline
\end{tabular}

Table 2-MICROSTRUCTURE OF THE EXPLOSIVE COMPOSITIONS

For $\mathrm{Cl}$ composition, the large pores lead to hot spots ignition and the coarse grains burn slowly. For $\mathrm{C} 2$, ignition is also obtained and the smaller grain size results in a faster pressure increase. In this case, the use of smaller grains increases the sensitivity of the explosive composition.

For C3, the voids are to small to produce an ignition of the explosive. In this case, a smaller grain size results in a lower sensitivity of the explosive composition. This phenomenon, called crossing of sensitivity, was previously experimentally observed [24] [25]. 


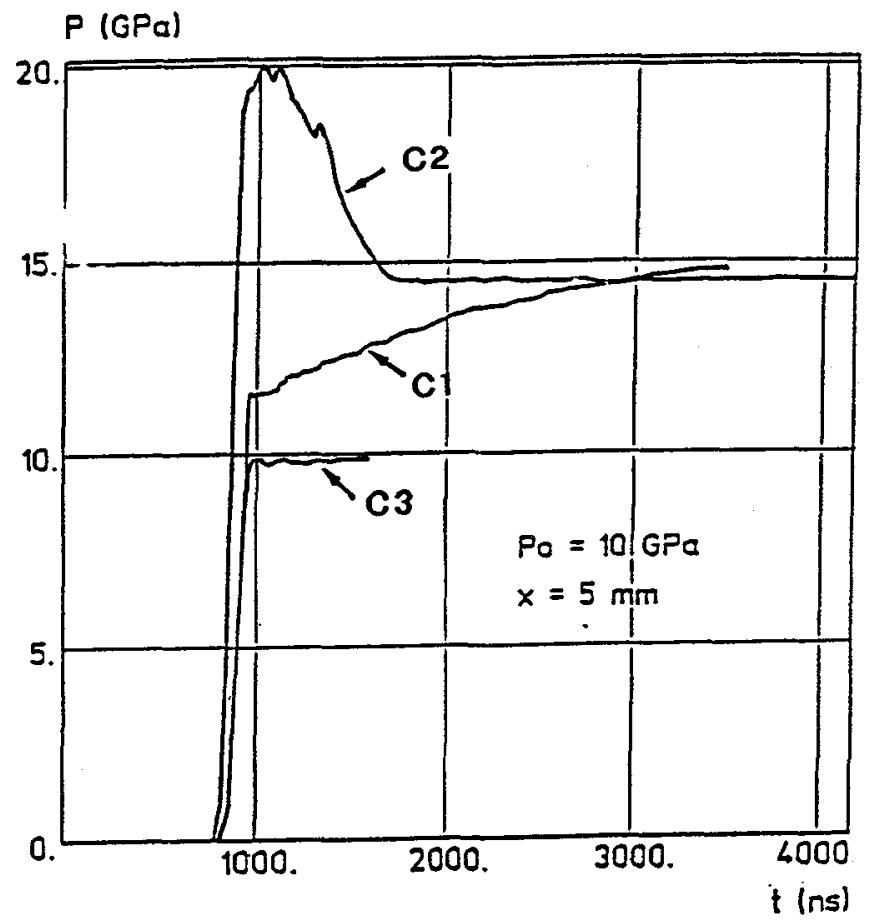

Figure 26 -EFFECT OF THE MICROSTRUCTURE ON THE SENSITIVITY OF EXPLOSIVE COMPOSITIONS

\section{5 - CONCLUSION}

We performed an experimental and theoretical study of hot spots creation in pressed explosive compositions.

Experimentally, it was found that hot spots formation and ignition are the result of the interaction of shock waves with microstructural voids. The mechanism governing the heat generation in the hot spots is the viscoplastic collapse of the porosity.

A physical model of hot spot generation and ignition was developed on the basis of this phenomenology.

Several applications were presented :

- analysis of the complex mechanisms governing the initiation of mixed HMX-TATB compositions,

- study of double-shock desensitization,

- development of a powerful kinetics taking into account the composition microstructure

In this kinetics, the hot spots model is associated with an efficient grain burning law.

The applications of such a model are in the areas of physics of explosives, safety studies and explosive composition formulation. 


\section{AKNOWLEDGEMENTS :}

We are deeply indebted with C. CASTILLE and E. GERMAIN who determined the origin of hot spots, M. NICOLLET who performed the impacts experiments, C. BIANCHI, M. LEROY and L. LEJAY who made the programs and performed the calculations.

\section{REFERENCES :}

[1] CASTILlE C., GERMAIN E., BELMAS R. - "Origine physique des points chauds dans les compositions explosives pressées au TATB", Propellants, Explosives, Pyrotechnics 17, 249-253 (1992).

[2] WALKER E.H. - "Derivation of the $\mathrm{P}^{2} \mathrm{~T}$ detonation criterion", 8 th symposium (international) on detonation, ALBUQUERQUE (1985).

[3] BELMAS R. - "Amorcage d'une composition explosive par sollicitations mécaniques rapides", 3ème Congrès de Pyrotechnie Spatiale, JUAN-LES-PINS (1987).

[4] MADER C.L., KERSHNER J.D. - "The three dimensional hot spot model applied to PETN, HMX, TATB and NQ", LA-10203-MX UC-45 (Septembre 1984).

[5] PARTOM Y. - "A void collapse model for shock initiation", 7th symposium (international) on detonation, ANNAPOLIS (1981).

[6] BELMAS R. - C.E.A. internal report.

[7] KHASAINOV, BORISOV A.A., ERMOLAYEV B.S.- "Shock wave predetonation processes in porous high explosives", 8th symposium (international) on detonation", ALBUQUERQUE (1985).

[8] MAIDEN D.E.- "A hot spot model for calculating the threshold for shock initiation of pyrotechnics and explosives", 3ème congrès de pyrotechnie spatiale, JUAN-LES-PINS (1987).

[9] FREY R.B. - "Cavity collapse in energetic materials", 8th symposium (international) on detonation, ALBUQUERQUE (1985).

[10] WACKERLE J., JOHNSON J.O., HALLECK P.M. - "Shock initiation of high density PETN", 6th symposium (international) on detonation. Office of Naval Research, ACR-211, ARLINGTON, VA (1970)

[11] HALLECK P.M., WACKERLE J. - "Dynamic elastic-plastic properties of single crystal pentaerythritol tetranitrate", Journal of Applied Physics, Vol 47, $\mathrm{N}^{\circ} 3$ (1976).

[12] BAER M.R. - "Numerical studies of dynamic compaction of inert and energetic granular materials", Journal of Applied Mechanics 36, Vol. 55 (mars 1988).

[13] BELMAS R., PLOTARD J.P., BIANCHI C., LEROY M., MEILLOT E., "Un modèle de points chauds fondé sur l'implosion de la porosité microstructurale", Propellants, Explosives, Pyrotechnics $18,217-222(1993)$. 
[14] NICOLLET M., BELMAS R., PLOTARD J.P., UDIMENT B., LEROY M. - "Amorçage par chocs simples et doubles d'une composition mixte TATB-octogène", Propellants, Explosives, Pyrotechnics 18, 128-131 (1993).

[15] BELMAS R., BIANCHI C., LEROY M. - "AMORC, un modèle physique d'amorçage par choc des explosifs", 4èmes Journées Détonique, BOURGES (1991).

[16] BELMAS R., PLOTARD J.P., BIANCHI C. - "A physical model of shock-to-detonation transition in heterogeneous explosives", Xth symposium (international on detonation), BOSTON (1993).

[17] LEE E.L., TARVER C.M - "Phenomenological model of shock initiation in heterogeneous explosives", Physics of fluids, Vol 4, 511-521 (1980).

[18] TARVER C.M., HALLQUIST J.O., ERICKSON L.M. - "Modeling short pulse duration shock initiation of solid explosives", 8th symposium (international) on detonation, ALBUQUERQUE (1985), NSWC MP 86-194 (1985).

[19] JOHNSON J.N., TANG P.K., FOREST C.A. - "Shock wave initiation of heterogeneous reactive solids", Journal of Applied Physics, Vol 57, 4323-4334 (1985).

[20] TANG P.K., JOHNSON J.N., FOREST C.A. - "Modeling heterogeneous high explosive burn with an explicit hot spot process", 8th symposium (international) on detonation, ALBUQUERQUE (1985),NSWC MP 86-194, 1985.

[21] CHERIN H., GOHAR P. - "The influence of grains morphology on the behavior of explosives", 9th symposium (international) on detonation, PORTLAND (1990).

[22] CHERIN H. - "Influence of microstructure on explosive compositions chemistry", Xth symposium (international) on detonation, BOSTON (1993).

[23] URTIEW P.A., ERICKSON L.M., ALDIS D.F., TARVER C.M. - "Shock initiation of LX-17 as a function of its initial temperature", 9th symposium (international) on detonation, PORTLAND (1990).

[24] MOULARD H. - "Particular aspect of the explosive particule size effect on shock sensitivity of cast PBX formulations", 9th symposium (international) on detonation, PORTLAND (1990).

[25] HONODEL \& al C.A. - "Shock initiation of TATB formulations", 7th symposium (international) on detonation, ANNAPOLIS (1981), NSWC MP 82-334 (1981). 